\title{
TOWARDS KNOWLEDGE MODELING AND MANIPULATION TECHNOLOGIES: A SURVEY
}

\author{
BIMBA ANDREW THOMAS \\ Faculty of Computer Science and Information Technology, University of Malaya, 50603 Kuala Lumpur. Malaysia. \\ bimba@siswa.um.edu.my \\ NORISMA IDRIS \\ Faculty of Computer Science and Information Technology, University of Malaya, 50603 Kuala Lumpur. Malaysia. \\ norisma@um.edu.my \\ AHMED AL-HUNAIYYAN \\ Computer \& Information Systems Department, Public Authority for Applied Education and Training, Kuwait. \\ hunaiyyan@hotmail.com \\ ROHANA BINTI MAHMUD \\ Faculty of Computer Science and Information Technology, University of Malaya, 50603 Kuala Lumpur. Malaysia. \\ rohanamahmud@um.edu.my.
}

AHMED ABDELAZIZ

Faculty of Computer Science and Information Technology, University of Malaya, 50603 Kuala Lumpur. Malaysia. ahmedaziz@siswa.um.edu.my

\section{SULEMAN KHAN}

Faculty of Computer Science and Information Technology, University of Malaya, 50603 Kuala Lumpur. Malaysia. sulemankhan1984@yahoo.com

VICTOR CHANG

International Business School Suzhou, Xi'an Jiaotong Liverpool University, Suzhou, China. ic.victor.chang@gmail.com

\begin{abstract}
A system which represents knowledge is normally referred to as a knowledge based system (KBS). This article focuses on surveying publications related to knowledge base modelling and manipulation technologies, between the years 2000-2015. A total of 185 articles excluding the subject descriptive articles which are mentioned in the introductory parts, were evaluated in this survey. The main aim of this study is to identify different knowledge base modelling and manipulation techniques based on 4 categories; 1) linguistic knowledge base; 2) expert knowledge base; 3) ontology and 4) cognitive knowledge base. This led to the proposition of 8 research questions, which focused on the different categories of knowledge base modelling technologies, their underlying theories, knowledge representation technique, knowledge acquisition technique, challenges, applications, development tools and development languages. A part of the findings from this survey is the high dependence of linguistic knowledge base, expert knowledge base and ontology on volatile expert knowledge. A promising technique for knowledge-based business management and other knowledge related applications is also discussed.
\end{abstract}

Keywords: knowledge acquisition; knowledge-based business; linguistic knowledge base; ontology; expert knowledge base; cognitive knowledge base.

\section{Introduction}

This article surveys several journal articles, conference papers, serials and books on the implementation and challenges of various knowledge modelling and manipulation technologies. It classifies these technologies according to their development theories and structure, resulting to four categories; the linguistic knowledge bases (Collin F Baker, 2014; Fellbaum, 1998; Speer \& Havasi, 2012), expert knowledge bases (Driankov, Hellendoorn, \& Reinfrank, 2013; Kerr-Wilson \& Pedrycz, 2016; Kung \& Su, 2007), ontology (Khan, 2009; Fensel, 2004; David Sánchez, 2010; Studer etal., 1998; Van Heijst et al., 1997) and most recently the cognitive knowledge base (Wang, 
2015b). Human knowledge is categorized at the levels of data, information, knowledge and intelligence. These categories are the fundamental cognitive objects in the human brain and cognitive systems (Wang, 2015). The development of computers that display an intelligent behaviour has been the foundation of Artificial Intelligence (AI).

A system which represents knowledge is normally referred to as a knowledge based system (KBS). The most important component of any knowledge based system is the knowledge base. Based on the characteristics of knowledge, Dignum \& vab de Riet (1991) defined a knowledge base as " $a$ set of statements that describe the knowledge about the truths of the actual world plus a set of constraints that describe statements that must be true in all possible worlds and statements that ought to be true in all possible worlds" (pp. 4).

In the past, KBS development has been viewed as a transfer of human knowledge into the implemented knowledge base (Wielinga et al., 1992). This view was based on the theory that the required knowledge already exists and only needs to be collected and implemented. Usually, the required knowledge is acquired by interviewing an expert, and implemented in the form of production rules. However, this approach did not support a suitable representation of different knowledge types (Studer et al., 1998). The existence of different types of knowledge and the absence of satisfactory justifications of the rules makes the maintenance process difficult and time consuming. Thus, this approach was only feasible in the development of small scale prototypes, thereby initiating a paradigm shift from the transfer approach to the modelling approach (Ramirez \& Valdes, 2012). The modelling approach is not intended on simulating the entire cognitive process of an expert, but to create a model which offer similar results in problem solving.

The main objective of this research is to survey existing knowledge base modelling and manipulation technologies, with the aim of identifying different knowledge representation, implementation and acquisition techniques. This survey could provide novice researchers with a tool to select appropriate knowledge representation and implementation techniques, while providing experts with a broader view to introduce novel techniques. Previous researchers have conducted surveys on knowledge based systems, for example, Liao (2003) did an analysis on knowledge management technologies and applications, Plant \& Gamble, (2003) discussed the important research in knowledge-based system life cycles and development, while Sahin et al., (2012) reviewed the current approaches and applications of hybrid expert systems. Our current review follows similar methodologies as the previous researchers. However, we focus on a broader aspect of knowledge modelling and manipulation technologies. To the best of our knowledge, this is the first study which provides a broad view on the various categories of knowledge modelling and manipulation technologies, their implementation and challenges. We suggest 8 research questions as shown in table 1. These questions are primarily centred around knowledge base modelling and implementations.

Table 1 Research Questions

\begin{tabular}{|c|c|c|}
\hline $\mathbf{S} / \mathbf{N}$ & Research Question & Motivation \\
\hline 1 & $\begin{array}{l}\text { What are the common approaches to knowledge } \\
\text { modelling and manipulation? }\end{array}$ & $\begin{array}{l}\text { Identify the various categories of knowledg } \\
\text { modelling and manipulation technologies }\end{array}$ \\
\hline 2 & $\begin{array}{l}\text { What are the theories supporting each knowledge } \\
\text { modelling approach? }\end{array}$ & $\begin{array}{l}\text { Identify the theoretical basis for the } \\
\text { implementation of each knowledge base } \\
\text { modelling approach }\end{array}$ \\
\hline 3 & $\begin{array}{l}\text { How is knowledge represented in each modelling } \\
\text { approach? }\end{array}$ & $\begin{array}{l}\text { Identify the various ways knowledge is } \\
\text { represented in each modelling approach. }\end{array}$ \\
\hline 4 & $\begin{array}{l}\text { Which knowledge acquisition technique is } \\
\text { commonly applied in each knowledge base } \\
\text { modelling approach? }\end{array}$ & $\begin{array}{l}\text { Identify the common knowledge acquisition } \\
\text { techniques used in each approach. }\end{array}$ \\
\hline 5 & $\begin{array}{l}\text { What are the common applications of each } \\
\text { knowledge modelling approach? }\end{array}$ & $\begin{array}{l}\text { Identify the types of applications for each } \\
\text { knowledge modelling approach }\end{array}$ \\
\hline
\end{tabular}


What are the implementation tools frequently used in each knowledge modelling approach?

7 What are the common challenges faced in knowledge modelling?

8

What are the programming language commonly used in each knowledge modelling approach?
Identify the various implementation tools used in each knowledge modelling approaches.

Identify the challenges of knowledge modelling technologies

Identify the various programming languages used in each knowledge modelling approaches.

The structure of the article is as follows: First, the outline of the survey process is discussed in section 2. In section 3 , we provide detail review of the knowledge base modelling and manipulation technologies. We give a detailed analysis of the results in section 4. Section 5 discusses the need for knowledge based business management. The directions for the further is highlighted in section 6 and the limitations of the survey in section 7. Finally, we present our findings and conclusions in section 8.

\section{Survey Process}

The articles included in our survey were extracted from 4 main digital database of academic journal articles. These digital libraries include Scopus, Web of Science, IEEE Xplore and ACM. These libraries were selected based on their impact evaluation and wide coverage of peer-reviewed journals in multiple academic disciplines. The inclusion of relevant articles in this survey was decided in 5 steps as shown in figure 1, using EndNote Desktop application. First, the digital libraries were searched based on keywords corresponding to the categories of knowledge base modelling technologies and the articles were restricted to publication between the year 2000 and 2015. Then, duplicated articles were removed. Articles published in both journals and conference proceedings, with the same title published by same authors, in the same year are regarded as duplicates. In this situation the article published in journal is selected, neglecting the one published in conference proceeding. Thirdly, the full texts of the remaining articles were searched online. This resulted to a reduced number of articles as seen in the third oval shape in figure 1. The fourth step involved relevance sorting, which required searching the full text based on some combination of keywords relevant to each category. Lastly, the remaining articles were read to identify information related to the different categories: knowledge base representation, implementation, acquisition technique, application, implementation tools and limitations. 


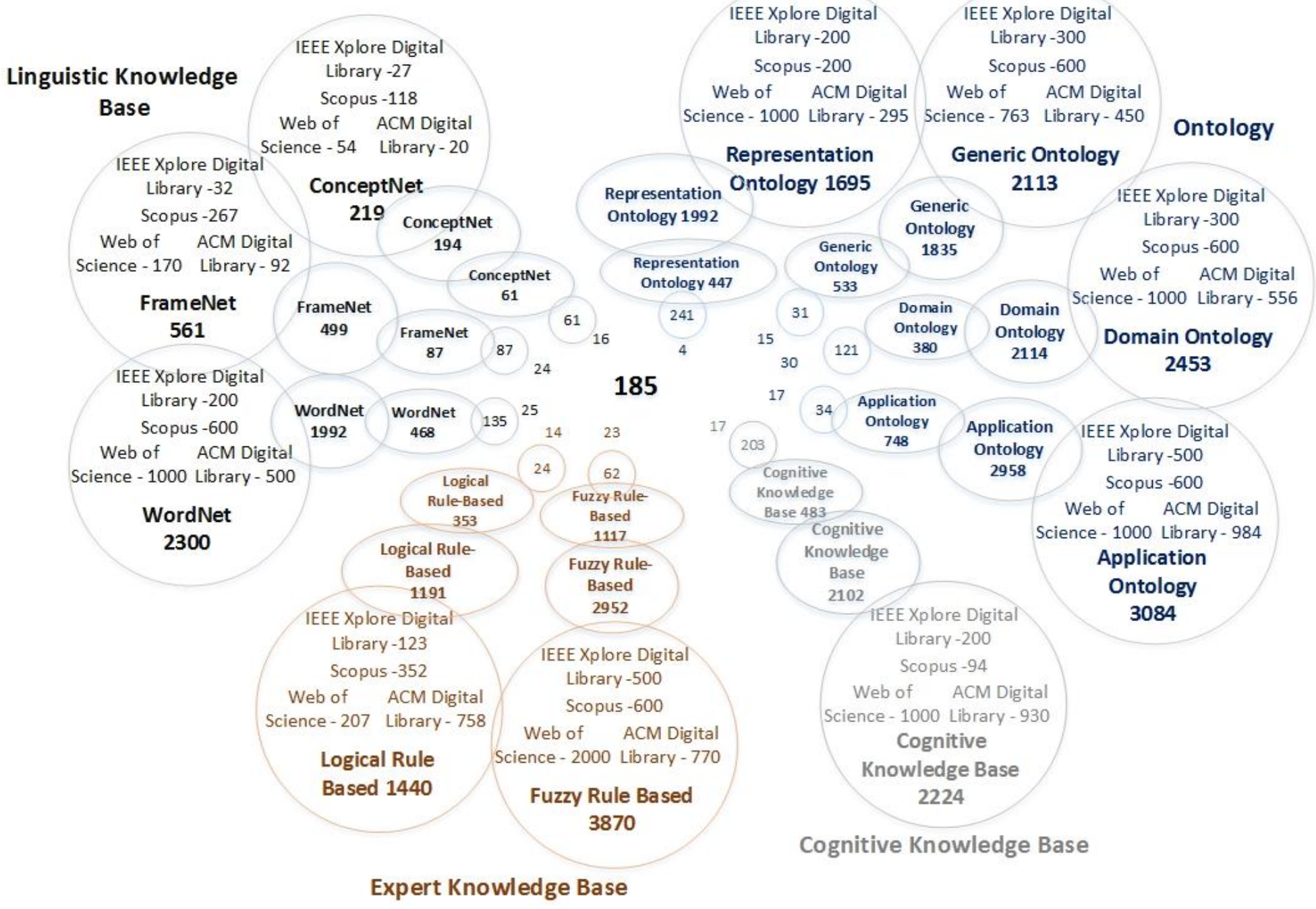

Figure 1 Survey Process

This process resulted to 185 articles, excluding the subject descriptive articles which are mentioned in the introductory parts. The analysed articles consisted of journal articles, conference proceedings, books and serials. They were examined based on the publication years, availability and relevance to the research domain.

\subsection{Classification of Knowledge Base Modelling Techniques}

Based on the fundamental theories of knowledge base modelling and manipulation, knowledge base technology can be categorized into four groups: 1) the linguistic knowledge bases (Baker, 2014; Fellbaum, 1998; Speer \& Havasi, 2012); 2) expert knowledge bases (Driankov et al., 2013; Kerr-Wilson \& Pedrycz, 2016; Kung \& Su, 2007); 3) ontology (Fensel, 2004; Sánchez, 2010; Studer et al., 1998; Van Heijst et al., 1997) and most recently 4) the cognitive knowledge base (Wang, 2015b). The various categories and types of knowledge base modelling 
approaches are shown in figure 2. In this section, we briefly explore each of these categories, with the aim of identifying and comparing the techniques and methodology used in representing and manipulating knowledge.

\subsection{Linguistic Knowledge Base}

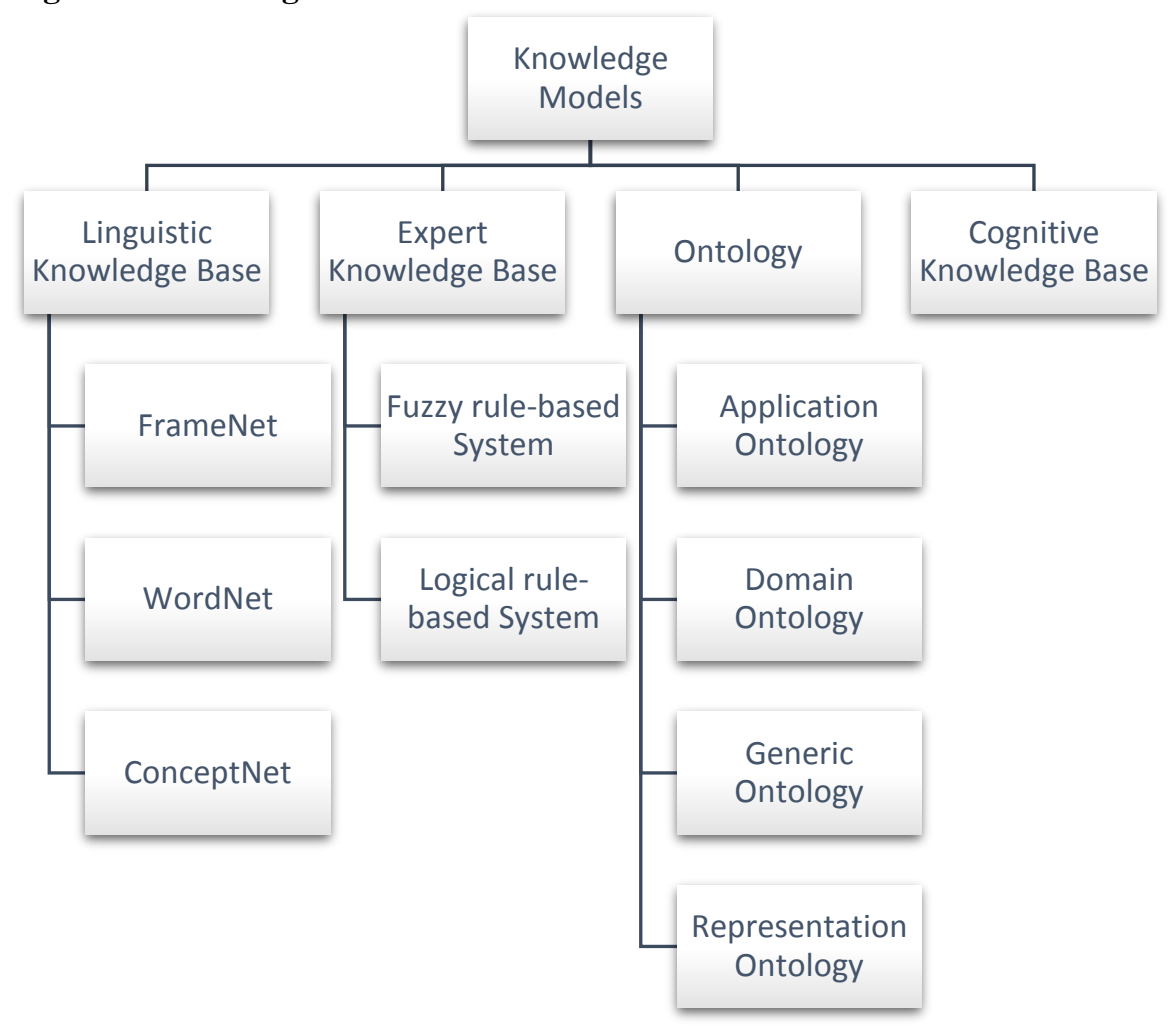

Figure 2 Classification of Knowledge Modelling and Manipulation Technologies

Language is a means through which human express thoughts, therefore to model human cognitive processes a lexicon is required. However, linguistic theories which attempt to model human grammar rely on data which is often not well documented (Fellbaum, 1998). Originally, liguists have divided the human knowledge of grammar into phonology, morphology, syntax, semantics and the lexicon. These aspects of grammar which are directed by clear rules allow computational linguistics to design parsers, that identify constituents of phrases and sentences, assigning a phrase structure to them. But, due to the large size of lexicon, there is a huge challenge in capturing the structure and properties of lexicon in a manner which reflects the actual human lexical knowledge (Fellbaum, 1998). Thus, making this an ideal research area for computational language modelling. Typical linguistic knowledge bases are lexical databases such as FrameNet, WordNet and ConceptNet (Wang, 2014). In the preciding sections, we will briefly describe this three lexical databases.

\subsubsection{FrameNet}

FrameNet (FN) was developed in an effort to build a lexicon of English that is comprehendible by both human and machine, using the theory of frame semantics and backed by means of an annotated corpus of lexical items (Baker, 2014; Fillmore et al., 2003; Lakhfif \& Laskri, 2015). The knowledge base structure of FN is defined as a relation between frames at various levels of generality. Frames are "script-like conceptual structure that describes a particular type of situation, object, or event along with its participants and props" (Ruppenhofer et al., 2006). Knowledge in FN is represented as frames and an annotated corpus (Baker, 2012; Wandmacher et al., 2011). 
Frames represent generalizations over groups of words which illustrate equivalent situations, similar set of roles and related syntactic behaviour (Martínez-Santiago et al., 2015; O'Hara \& Wiebe, 2009). In the theory of frame semantics, the roles or common situations which describes a frame are called frame elements (Das et al., 2014; Pimentel et al., 2012). The association between a word form and its meaning is referred to as a lexical unit (Zhang et al., 2015). Word form is a lemma and a given part of speech, while the meaning is represented by a semantic frame and a definition (Baker, 2014). The procedure for creating lexical entries in FrameNet is well explained by (Boas, 2005).

Knowledge acquisition in FN is a manual process of grouping words with semantic overlap according to some explicit criteria to form frames and sentence annotation based on multiple annotation layers (Kettnerová et al., 2008). The annotation process involves FN lexicographers to declare each word in a sentence as a target, then select a frame related to the target, get a set of annotation layers and appropriate frame element tags and the annotate the relevant constituents (Ruppenhofer et al., 2006).

FN version 1.3, is a freely available lexical database which contains a wealth of semantic knowledge of about 1161 Semantic Frames, covering more than 12,600 lexical units, documented with nearly 200,000 manual annotations (Lakhfif \& Laskri, 2015). FN is developed based on the eXtensible Markup Language (XML) (Martínez-Santiago et al., 2015). Raw sentences are annotated and converted to XML, using a Java GUI client, and then inserted into tables in a MySQL database (Baker, 2012). FN corpus can be assessed using the Natural Language Toolkit (NLTK) in Python (Garrette \& Klein, 2009). The data in FN has been used to develop automatic semantic role labellers (Croce \& Basili, 2011; Erk \& Pado, 2006; Giannone, 2013; Gildea \& Jurafsky, 2002; Padó \& Lapata, 2009) and frame-semantic parsers (FSP) (Das et al., 2014). Other end-user applications for FN includes Question answering (QA) (Ofoghi et al., 2008a, 2008b; Sinha, 2008) and information extraction (IE) (Mohit \& Narayanan, 2003; Scaiano \& Inkpen, 2009). Discourse interpretation (DI) can be supported using existing knowledge in FN (Irmer, 2013).

However, since FN is built on edited text, applying an automatic sematic role labeller (SRL) trained on its current data could give poor results for text such as Twitter feeds (Baker, 2014). Currently, there is no unified annotation model across FNs (Gruzitis \& Dannélls, 2015). Compared to WordNet, FrameNet has a rather limited lexicon (Baker, 2012). Text coherence cannot be handled by FN because it works strictly within the sentence, this makes it impossible to link arguments across sentences (Ruppenhofer et al., 2010). Another limitation of FN is its inability to represent negation and conditional sentences. A major challenge faced now by FN is finding a more cost-effective way to expand, while preserving the richness and accuracy of its annotation. Another challenge is finding ways to combine the frame semantic work currently being carried out around the world, to generate a truly multi-lingual FN (Gruzitis \& Dannélls, 2015).

\subsubsection{WordNet}

WordNet (WN) is another large scale electronic lexical database conceived based on human semantic organization, where words and their meanings are related to one another via semantic and lexical similarities (Fellbaum et al., 2006). WN is a "proposal for a more effective combination of traditional lexicographic information and modern high-speed computation" (Miller et al., 1990). Unlike FN, this model was constructed based on word association norms, where given a lexical stimulus such as a noun, verb or adjective, responses often remain in specific semantic relations such as synonyms (similar), antonyms (opposite), hyponyms (subordinate) / hypernyms (superior) and meronyms (part) / holonyms (whole) (Fadaee et al., 2013; Fellbaum et al., 2006; Lindén \& Niemi, 2014; Marrafa, 2002). For example, "bird" can elicit its hypernym "animal" or its meronym "feather". Such human associated responses revile the way mental lexicon is organized. Knowledge in WordNet is represented as a semantic network formed by synsets (cognitive synonyms) (Lee, Huh, \& McNiel, 2008). A set of synonyms that serve as identifying definitions of lexicalized concepts are referred to as synsets (Maziarz et al., 2013; Montejo-Raez et al., 2014). Similar to FN, the lexical units in WN tend to be derived from their connection with other members of the same synset as well as from their lexical-semantic association with other synsets (Marrafa, 2002; Saif et al., 2015; Wei et al., 2015). The entries in WN are strictly separated based on syntactic categories of Noun, Verb, Adjective and Adverbs only (Dragoni et al., 2015; Uddin et al., 2013). 
In WN, lexicon is constructed essentially through automated acquisition or hand-crafted. The manual process is slow, expensive and cumbersome, however it allows one to create entries that will be useful to certain applications. The Lexicosyntactic Pattern Extraction (LSPE) method is one of the automated approaches used by lexicographers in developing domain-dependent knowledge base (Fellbaum, 1998). The technique does not require a knowledge base or complex interpretation modules to suggest new WordNet relations. But, the results provided by LSPE are not comprehensive.

Similar to FN, WN is a freely available lexical database. WordNet 3.0 comprise of 155,287 unique strings with 117,659 synsets and 206,941 word-sense pairs. WN has been converted to Resource Definition Framework (RDF) and Web Ontology Language (OWL), in order to improve interoperability between software applications that use WN (Van Assem et al., 2006).

Using a W3C standard language SPARQL Protocol and RDF Query Language (SPARQL), WN data in RDF/OWL format can be queried (Brenga et al., 2015; Prud'Hommeaux \& Seaborne, 2008). Typical queries can pose on WN RDF/OWL once it is loaded in tools such as SWI Prolog's Semantic Web Library (Wielemaker et al., 2008) or Sesame (Broekstra et al., 2003). Some WN-based word similarity algorithms have been implemented in a Perl package called WordNet::Similarity (Pedersen et al., 2004), Python package called NLTK (Bird, 2006) and Align, Disambiguate and Walk (ADW) in Java (Pilehvar \& Navigli, 2015) .

There are various projects which have utilized WN, for example, 1) BabelNet, a multilingual lexical database in which WordNet is combined with Wikipedia to perform multilingual word sense disambiguation and semantic relatedness (Navigli, 2013); 2) EuroWordNet consists of wordnets from several European languages resulting in a multi-lingual database used for multi-lingual information retrieval (Vossen, 1997) and 3) MultiWordNet, an Italian WordNet which is strictly aligned to English WordNet, while retaining its ability to represent true lexical peculiarity between languages (Pianta et al., 2002).

WN is commonly used to improve text clustering (TC) (Wei et al., 2015). In Word Sense Disambiguation (WSD), WN combined with other techniques is been applied as a knowledge base approach to solve ambiguous meaning of words in Information Retrieval (IR) (Kilinc \& Alpkocak, 2011; Sachdeva et al., 2014; Tyar \& Win, 2015) . Nevertheless, WN poses some limitations due to its connotation inconsistencies and exceedingly fine granularity of senses (Erjavec \& Fišer, 2006; Prakash et al., 2007).

\subsubsection{ConceptNet}

ConceptNet $(\mathrm{CN})$ is a large-scale common-sense knowledge base which describes human knowledge and how it is expressed as a semantic graph (Agarwal et al., 2015; Liu \& Singh, 2004; Speer \& Havasi, 2012). While lexical databases such as WN is developed for lexical categorization and word-similarity determination and FN is optimized to describe a particular type of situation and event, $\mathrm{CN}$ is used for making practical context-based inferences (Schuller \& Knaup, 2011). The main goal of developing CN is to capture common-sense knowledge that describe the real world (Hsu et al., 2006; Wu \& Tsai, 2014). While FN represent knowledge in form of frames and $\mathrm{WN}$ in form of a semantic network of synsets, $\mathrm{CN}$ represents knowledge in form of graph, where the nodes include higher-order compound concepts composed of action verbs (Bicocchi et al., 2011). It extends WN's repository of semantic relations from triplet of synonyms to twenty semantic relations (Liu \& Singh, 2004). Unlike $\mathrm{WN}$, the knowledge in $\mathrm{CN}$ is more informal, defeasible and practically valued for example, HasEffect ('eating chili', 'stomach ache') (Hsu et al., 2008; Noah et al., 2010). CN conveys concepts, that are words and phrases which could be extracted from natural language text, along with statements of the ways in which these concepts relate to each other (López et al., 2011; Majewski \& Szymański, 2008; Speer \& Havasi, 2012).

Knowledge in $\mathrm{CN}$ is acquired automatically from the English sentences in the Open Mind Common Sense (OMCS) corpus. It then applies an additional set of procedures to optimize the connectivity of the semantic network (Liu $\&$ Singh, 2004). These processes include; extraction, normalization and relaxation. As at 2012, CN contains 12.5 million edges, representing about 8.7 million statements connecting 3.9 million concepts (Speer \& Havasi, 2012). Access to CN data is provided by a web API using JavaScript Object Notation (JSON) textual data format (Baydinet al., 2015). Similar to WN, CN was encoded in RDF/OWL language to make it accessible and integrated with Semantic Web applications (Grassi \& Piazza, 2011). 
$\mathrm{CN}$ tool-kit has been used in developing several applications, such as: 1) LifeNet, a probabilistic graphical model of everyday first-person human experience (Singh \& Williams, 2003); 2) Emotus Ponens, a textual affect-sensing system that leverages common-sense to classify text using six basic emotion categories (Liu et al., 2003) and 3) GOOSE, a goal oriented search engine for novice users (Liu et al., 2002). CN has been used to improve feature selection in machine learning approaches (Agarwal et al., 2015). The process of selecting meaningful navigational paths in knowledge discovery (KD) can be improved by using CN as a common-sense KB (Freitas et al., 2015). $\mathrm{CN}$ is used as a framework to transmit sentiment values for building sentiment dictionaries (Tsai et al., 2013). Latent Dirichlet Allocation (LDA) has been combined with $\mathrm{CN}$ to measure similarities between terms in twitter event classification (Vo et al., 2015). However, the coverage of CN's knowledge is shallow as compared to human knowledge.

\subsection{Expert Knowledge Base}

Expert knowledge base consists of useful domain knowledge for problem solving. This knowledge is represented as a set of rules in the expert knowledge base. Rules are viewed as a relatively easy technique to represent knowledge. Any rule consists of two parts: the IF part called the antecedent and the THEN part called the consequent. Practically, a rule can have multiple antecedents joined by conjunction (AND) or disjunction (OR) or a combination of both. The antecedent of a rule incorporates two parts; a linguistic object and its value. The object and its value are linked by an operator. The operator identifies the linguistic object and assigns the value. Rules can represent relations, recommendations, directives, strategies and heuristics (Negnevitsky, 2005). Expert knowledge bases are categorized as logical rule-based (LRS) and fuzzy rule-based (FRS) systems. Details of each rule-based knowledge base are discussed in the following sections.

\subsubsection{Logical Rule-Based System}

Knowledge is represented as binary logic in a logical rule-based system (Park, 2003; Rattanasawad et al., 2013; Selva et al., 2014). In this system, if the antecedent is true, then the consequent is also true (Negnevitsky, 2005). Mostly, in a LRS, knowledge is acquired manually from domain experts through interviews, where experts communicate their knowledge using questionnaires (Connaghan et al., 2013; Dimitroula et al., 2001; Selva \& Crawley, 2012). However, knowledge in forms of rules can be acquired automatically, such as RUBRIC which constructs rules from thesauri (Minkoo et al., 2000) and semi-automated like KnowRob, which automatically acquires information from different knowledge sources with the aid of human for correcting mistakes and aligning imported knowledge sources (Tenorth \& Beetz, 2013).

Logical rule-based systems have been applied in a number of areas such as, hole maching (Park, 2003), flouorescein angiography (Dimitroula et al., 2001), bridge crane control (Capella et al., 2003), estimating infant immunization coverage (Kowalski \& Burton, 2012), Lungs abnormality detection (Lahouar et al., 2012), text extraction system (Ramakrishnan et al., 2012), decision support (Selva \& Crawley, 2012) and power grid dispatch and control (H. Zhang \& Zou, 2012). Prolog is the programming language used mostly for knowledge representation in logical rule-based systems, as seen in WUENIC (Kowalski \& Burton, 2012), sports coaching (Connaghan et al., 2013), KnowRob (Tenorth \& Beetz, 2013) and online poker agent (Teofilo et al., 2014). Other development tools used are CLIPS, for the implementation of FUNAGES (Dimitroula et al., 2001).

However, the process of knowledge acquisition is similar to ontologies where it is highly dependent on volatile domain expert knowledge, which is sometime complete and incomplete, precise and imprecise or certain and uncertain (Liu et al., 2013). In addition, capturing an expert's knowledge entirely is difficult as most of their knowledge is hidden in their skills (Selva \& Crawley, 2012).

\subsubsection{Fuzzy Rule-Based System}

Fuzzy sets are used in representing knowledge in a fuzzy rule-based system (Cordón, 2011). Unlike rule-based systems, in fuzzy rule-based system, if the rule antecedent is true, then the consequent could be partially true. It provides an efficient knowledge representation method for systems that involve continues variables (Banerjee et al., 2001). Fuzzy logic is developed as a method to express and apply human knowledge in a form that reflects an 
expert's thinking, which is represented by terms such as generally, rarely, sometimes, often and occasionally (Negnevitsky, 2005).

Knowledge acquisition in fuzzy systems can either be from human experts or data-driven (Bombardier et al., 2007; Zajaczkowski \& Verma, 2012; Zhang \& Mahfouf, 2011). The human expert approach lends itself to a manual design of fuzzy models based on existing knowledge retrieved from an expert through interviews and open questions (Fay, 2000). On the other hand, the data-driven method identify the structure and parameters of fuzzy models from datasets using various methods such as feature space mapping and C4.5 classification tree (Duch et al., 2001), fuzzy rule learning algorithm (Fernandez et al., 2010), fuzzy scheduler (Prado, et al., 2010), swam intelligence approach (R. Prado et al., 2010; Zhang \& Mahfouf, 2011), differential evolution learning (Prado et al., 2011) and genetic algorithm (Nurnberger, 2004; Ozyer et al., 2007).

Fuzzy rules have been used to represent knowledge in several domains such as railway operation control systems (Fay, 2000), time series prediction (Paul \& Kumar, 2002) Hepatitis medical diagnosis, classification system (FRBCSs) (Fernandez et al., 2010), bioinformatics (Zhou et al., 2012), grid computing (Prado et al., 2010), economic analysis of RFID orders (Ustundag et al., 2010), prediction of mechanical properties of alloy steel ( Zhang \& Mahfouf, 2011), bioinformatics (Nurnberger, 2004; Zhou et al., 2012), eco-system management (Adriaenssens et al., 2004), finance (Boyacioglu \& Avci, 2010), to study HIV evolution in infected individuals (Jafelice et al., 2009) and robotics (Bai et al., 2005).

Fuzzy production rules in expert systems can be represented using Fuzzy Petri net (Fay, 2000; Liu et al., 2013). Java programming language has also been used to develop a software tool which supports the design and computation of recurrent fuzzy systems (Nurnberger, 2004). Natural language information analysis method and object role modelling have been applied in creating symbolic fuzzy models representing customer knowledge in a defect recognition system (Bombardier et al., 2007). Definition of membership functions and values captured from human experts, can also be represented using MATLAB fuzzy logic toolbox simulator (Celikyilmaz \& Turksen, 2008; Guimaraes \& Lapa, 2007; Jafelice et al., 2009). One of the challenges of fuzz rule-based system development is the lengthy process of rule elicitation and every procedure is specific to each application (Banerjee et al., 2001) . (Pandey \& Mishra, 2009).

\subsection{Ontology}

Ontology, a branch of metaphysics dealing with the nature of being, is the third approach to knowledge modelling and manipulation presented in this survey. While linguistics knowledge models represent knowledge by lexical and semantic relationships and expert knowledge models by logical and fuzzy rules, ontologies represent knowledge as a taxonomy of concepts with their attributes, values and relations (Studer et al., 1998). The main aim of ontologies is to provide a platform which facilitates the sharing and reuse of knowledge between groups in a computational form (Apisakmontri, Nantajeewarawat, Ikeda, \& Buranarach, 2016). As Studer et al. (1998) defines ontology as "a formal, explicit specification of a shared conceptualization." "Conceptualization" refers to an identification of relevant concepts of an abstract model of some phenomenon in the world. While "Explicit" means the concepts identified and the constrains on their use are explicitly defined (Kimble, et al., 2016). Ontologies are made of at least three elements: 1) classes (domain concepts); 2) relations (distinctive sorts of parallel relationship between concepts); and 3) instances (real world phenomenon) (David Sánchez, 2010). Most researchers agree on classifying ontologies based on different generality levels and conceptualization (Borst, 1997; Maalel et al., 2012; Ramos, 2015; Studer et al., 1998; Van Heijst et al., 1997; Zhang et al., 2004; Zhang et al., 2011). This resulted to the four categories of ontologies discussed in this survey, which are application ontology, domain ontology, generic ontology and representation ontology.

\subsubsection{Application Ontologies}

Application ontologies, capture all the necessary characterizations required to model knowledge for a particular domain. However, application ontologies have method and task specific extensions (Jin Tan et al., 2005; Savonnet et al., 2015; Simperl, 2009; Van Heijst et al., 1997). An application ontology describes the relationship between concepts based on specific tasks (Liu et al., 2010). This can be seen from its application in courseware management for teachers (Jin et al., 2005), indexing (Assali et al., 2007), OntoNeuroBase which is used as a 
common semantic reference for aligning heterogeneous data in neuroimaging (Temal et al., 2008), smart homes (Chen et al., 2009), comparing UML elements type in class diagrams (Robleset al., 2012) and intrusion detection system (Meneses et al., 2015).

Knowledge acquisition in application ontologies involve eliciting reasoning mechanisms used by an expert to do a task or solve a particular problem. Semi-automated techniques have been used to elicit knowledge from documents, technical reports and expert interviews, combined with an inferential modelling technique which supports the knowledge engineer in identifying different knowledge types (Chan, 2004b). However, Legaz-Garcia et al. (2012) developed an application ontology automatically, reusing different ontologies to describe genomic sequence and genetic disorders (Legaz-García et al., 2012).

In application ontology development, Protégé is the most commonly used tool for representing concepts and their relations (Assali et al., 2007; Jin Tan et al., 2005; G. Liu et al., 2010). Other tools used are Goal-Oriented Application Ontology Development Technique "GAODT" (Santos et al., 2013), Knowledge Modelling System (KMS) (Chan, 2004a) and Model Driven Architecture (MDA) (Santoso et al., 2011). The common programming language used in application ontology development is the Web Ontology Language (OWL) (Durbha et al. 2009; Ye et al., 2011). However, Resource Definition Framework (RDF) and OWL have been combined to convert cause-effect relationships of a concept while developing application ontologies (Ebrahimipour \& Yacout, 2015).The major challenge of application ontologies is its reusability (Van Heijst et al., 1997). There is an essential need for developing tools which support application ontology reuse processes and the need for a task approach to application ontology reuse (Simperl, 2009).

\subsubsection{Domain Ontologies}

Domain ontologies represents conceptualizations that are valid only in a specific domain for example education (Labidi \& Sergio, 2000; Mesarić \& Dukić, 2007), health care (Batet et al., 2011; Castilho et al., 2008), manufacturing (El-Diraby \& Osman, 2011) and environmental studies (Ceccaroni et al., 2004; Mercantini \& Faucher, 2012). The main aim of domain ontologies is to eradicate the conceptual and terminological misperception amongst members of a specific community, who need to share documents and information (Navigli \& Velardi, 2004).

Several techniques have been proposed for knowledge acquisition in domain ontology construction. The CommonKADS methodology was used to formalize the knowledge acquisition process, where the main concepts and characteristics of the domain where extracted manually from experts (teachers) using a questionnaire (Labidi $\&$ Sergio, 2000). However, OntoLearn system automatically extracts domain terminologies from texts and filters them using Natural Language Processing (NLP) and statistical techniques (Navigli \& Velardi, 2004). Soo-Yeon et al. (2004), proposed a semi-automatic method for constructing domain ontology. First a corpus was developed from web documents in the pharmaceutical domain, then concepts were extracted using NLP, afterwards hierarchical structures representing relationships between terminologies were formed. A fully automated approach for domain ontology construction was taken by (Chen et al., 2008). Using Single Value Decomposition (SVD), Adaptive Resonance Theory Network (ART) and Boolean operation, meaningful terms are extracted from domain-related web pages to automatically construct domain ontology. Another automated approach was taken by (Sánchez \& Moreno, 2008). Through unsupervised methodology, non-taxonomically related concepts and relationships were extracted from a web corpus.

Domain ontology has been applied in student modelling and knowledge domain construction in collaborative learning system (Labidi \& Sergio, 2000). Other applications include information retrieval (Assali et al., 2007), geological hazards (Liu et al., 2010) and data mining (Mansingh et al., 2011). More specifically, domain dependant ontologies are used to support information exchange processes in advertising networks (Al-Safadi \& Al-Abdullatif, 2010). They have also been applied in representing antimicrobial treatment rules and providing feedback while prescribing antibiotic (Bright et al., 2012). Scenario Object Model (SOM), a domain ontology, is used for finding, retrieving, auditing, sharing and analysing recorded information from hazard evaluation procedures (Wu et al., 2013). 
Various tools for the construction of domain ontology has been introduced. SymOntos support the construction of ontologies using the OPAL (Object, Process, Actor modelling language) methodology (Missikoff et al., 2003). Unified Modelling Language (UML) has also been used for the design of domain ontology models of multi-agent systems (Wei et al., 2003). Property and Class characteristics from Text for Ontology Enrichment (PACTOLE), is used to develop domain ontology by deriving concept lattice from a structured context, forming a binary table which represents a set of objects with their properties (Bendaoud et al., 2008). GRAONTO offers a graph-based approach for automatically constructing domain ontologies (Hou et al., 2011). Zhang \& Ma (2014) proposed a tool that transforms eXtensible Markup Language (XML) to ontologies, making it easier to utilize XML data on the web. Similar to application ontology, Protégé can also be used to develop domain ontology (Semenova \& Kureychik, 2015). The most language used in domain ontology development is the OWL (Durbha \& King, 2004; Ochoa et al., 2013; She \& Wang, 2009; Soo-Yeon et al., 2004; Su et al., 2005). However, defining ontologies for serving multiple users and application is hard to create and manage (Mena et al., 2000). In complex domains, the task of constructing ontologies are usually controversial due to different expert points of view (Missikoff et al., 2003). Subsequently, there is a lack of standardized methodology for building domain ontology (Huang \& Gao, 2009).

\subsubsection{Generic Ontologies}

Generic ontologies sometimes referred to as top-level ontologies, are usually valid over various domains (Santoso et al., 2011; Xing et al., 2009; Ye et al., 2011). They define concepts like state, event, process, action, component etc. For example, generic ontologies are used in multi-agent systems, permitting agents to interoperate and cooperate through a common ontology ( $\mathrm{Su}$ et al., 2003). PRIMA is another generic ontology which contains a set of concepts and relations describing risk and its incorporation in various work processes (Makki et al., 2008). Also generic ontologies are used for creating models for policy-based regulations, which incorporate different domains like Food and Drug Administration (FDA), financial regulation, contracts and individuals conducting business (El Kharbili \& Stolarski, 2009). The Open Group Architecture Framework (TOGAF) generic ontology contains knowledge about an enterprise based on four domains of business, data, application and technology (Czarnecki \& Orłowski, 2010). CoBra ontology aids the pervasive computing environment where different intelligent agents with specific task exchange knowledge and cooperate to reach their goals (Chen et al., 2003).

Knowledge acquisition in generic ontologies is difficult to fully automate, because it involves information scattered in different systems and services. Thus, it is mostly semi-automatic, involving a human expert combined with statistical, syntactic and semantic techniques (Makki et al., 2008). Kohli et al. (2012) manually extracted information using literature reviews, interviews and surveys from experts to develop the generic slum ontology (GSO), which comprises of concept that refer to the morphology of the environment. EmotionsOnto, a generic ontology used to detect and describe emotional expressions, manually acquires information from users (Gil et al., 2015).

OntoEdit and Protégé were used to develop OBELIX, a generic service ontology which represents a formalization of concepts on service management and marketing (Akkermans et al., 2004). Similar to application ontology, Protégé is the most common tool used in the development of generic ontology (Czarnecki \& Orłowski, 2010; Darmoul et al., 2011; Dutra et al., 2010; El-Subaihi et al., 2013; Marwat et al., 2014). The OWL language is also used in generic ontology development, because of its adoptability, decidability and efficiency (Dutra et al., 2010; Marwat et al., 2014). However, generic ontology development is still encountering some challenges in knowledge acquisition and lack of sufficiently validated and generalized development methodology (Marwat et al., 2014).

\subsubsection{Representation Ontologies}

Representational ontologies are not restricted to a particular domain. This kind of ontologies present entities without declaring exactly what ought to be represented. These type of ontologies capture knowledge in a problemsolving independent way (Studer et al., 1998). The major application of ontologies is in the semantic web, which provides a platform for automatically processing data and information using extensible metadata (Feilmayr \& Wöß, 2016). The Mediation Bridge Ontology (MBO) is a representation ontology used to store the correspondences between matching ontologies, enabling interoperability in the semantic web (Khan et al., 2015). Another example of a representation ontology is proposed by (Benslimane et al., 2005) for semantic 
interoperability of information sources. It uses semantic mediation to allow definition of sharing system, interrogation, uniform and transparent access to diverse information sources.

Knowledge acquisition in ontologies are mostly done manually. Traditionally, the creation of the content of ontologies such as concepts and relations are done by knowledge engineers or domain experts (Zhou, 2007). However, representation ontologies usually define a set of concept representations of generic and domain ontologies (Maalel et al., 2012). Thus, supporting an automatic knowledge acquisition process. To construct representation ontologies, the description logic and stamping technique are used (Benslimane et al., 2005). The stamping technique allows multiple representation of the same concept, allowing a phenomenon to be used in one or more context. Similar to the other types of ontologies mentioned, the representation ontology lacks standard development methodology.

\subsection{Cognitive Knowledge Base}

Conventional technologies for knowledge base modelling and manipulation such as linguistic knowledge base, expert knowledge base and ontology are man-made rather than machine built. "The absence of thorough and sufficient operations on acquired knowledge, inflexible for learnt knowledge synergy, and weak transformability among different knowledge bases gave rise to a novel approach, the cognitive knowledge base" (CKB) (Wang, 2015a). Based on the previous studies in cognitive science and neurophysiology (Hampton, 1997; Leone et al., 2006), "the foundations of human knowledge in the long-term memory can be represented by an object-attributerelation model based on the synaptic structure of human memory, which represents the hierarchical and dynamic neural clusters of knowledge retained in memory as well as the logical model of knowledge bases" (Wang, 2014). The cognitive knowledge base is a structure that manipulates knowledge as a dynamic concept network like the human knowledge processing (Wang, 2008; Wang et al., 2011). In CKB a concept is a cognitive unit which identifies and models real-world concrete entities and a perceived-world (abstract entity) (Pojman, 2001; Wang, 2015a). The basic unit of knowledge in a CKB is a formal concept represented as an OAR model according to concept algebra (Valipour \& Yingxu, 2015; Wang, 2007; Wang, 2015a). While complex knowledge such as a theme are represented as multiple associate concepts, which forms a partial dynamic concept network (DCN).

The CKB structure consist of the logical model, physical model, linguistic knowledge base and knowledge manipulation engine. The logical model of knowledge bases shared by humans and cognitive systems is known as the object-attribute-relation model (Wang, 2014). The logical structure is modelled as a hierarchical network of concepts and themes. The logical knowledge base represents knowledge as Cartesian products of formal concepts. The physical knowledge base implements the memory structures of knowledge as a DCN. The linguistic knowledge base comprises of the initial words as modelled in WordNet and the representation of these words and their relation in form of the OAR model.

The CKB is managed by the knowledge manipulation engine (KME), which handles knowledge acquisition, fusions and retrievals such as concept match, relational concept identification and knowledge differentiation (Wang, 2014). Similar to WordNet, the relations among formal concepts are classified as synonyms, antonyms, hyponyms and hypernyms. The knowledge retrieval from CKB is supported by the concept and theme visualization processes.

The cognitive processes of concept memorization and knowledge fusion, similar to human and cognitive systems learning processes, are used for knowledge acquisition in CKB (Wilson \& Keil, 2001). Concept memorization involves acquiring concepts based on the formal concept model (Wang, 2014). While, knowledge fusion mimics the mechanism of human learning and knowledge memorization similar to buffered knowledge in the short-term memory before moved to the long-term memory (Wang, 2014).

Web knowledge discovery engine is developed based on concept algebra (CA), simulating the cognitive knowledge representation in the brain (Hu \& Wang, 2007). Cognitive knowledge base has also been used to develop AutoLearner, a machine learning system and a cognitive simulator. It visualizes the interactions between internal knowledge representation as well as the thinking and learning processes (Hu \& Wang, 2007b). A text knowledge representation method based on CA is used to automatically extract concepts from text and establish 
relations between concepts (text association rule mining) (Ye et al., 2013). To automatically implement information restructuring of web documents, knowledge in informal documents are converted to cognitive knowledge represented by CA and concept networks (Hu \& Wang, 2007a). In order to improve the semantic properties of knowledge represented in oil companies, an oilfield enterprise knowledge management system based on concept algebra was proposed (Duan et al., 2013).

The Visual Simulator of Concept Algebra (VSCA) tool developed in the MATLAB environment provides a means to explicitly simulate and visualize mathematical concepts (Lin \& Wang, 2014). Concept networks can be visualized with concept graphs using an open source library, Java Universal Network/Graph(JUNG) (Hu \& Wang, 2007). A formal knowledge representation system (FKRS) which supports autonomous concept generation based on CA was implemented in Java (Tian et al., 2011). Another tool used for visual knowledge representation of concepts, which enables autonomous learning of concepts by machines was developed using java (Tian \& Wang, 2007).

\subsection{Results and Evaluation}

A total of 185 articles which included 3 books, 22 serials, 50 conference proceedings and 110 journal articles were evaluated in this survey. The publication years of these articles are from 2000 to 2015 . We present our results in the following subsections based on the research questions presented in table 1.

\subsection{Evaluation of Knowledge Base Modelling Approaches}

In this survey, we identified the common approaches to knowledge base modelling and manipulation. figure 3 , represents the publication years versus related articles on the types of knowledge base modelling categories used in this survey. The aim is to identify the categories of knowledge modelling and manipulation technologies and detect possible trends.

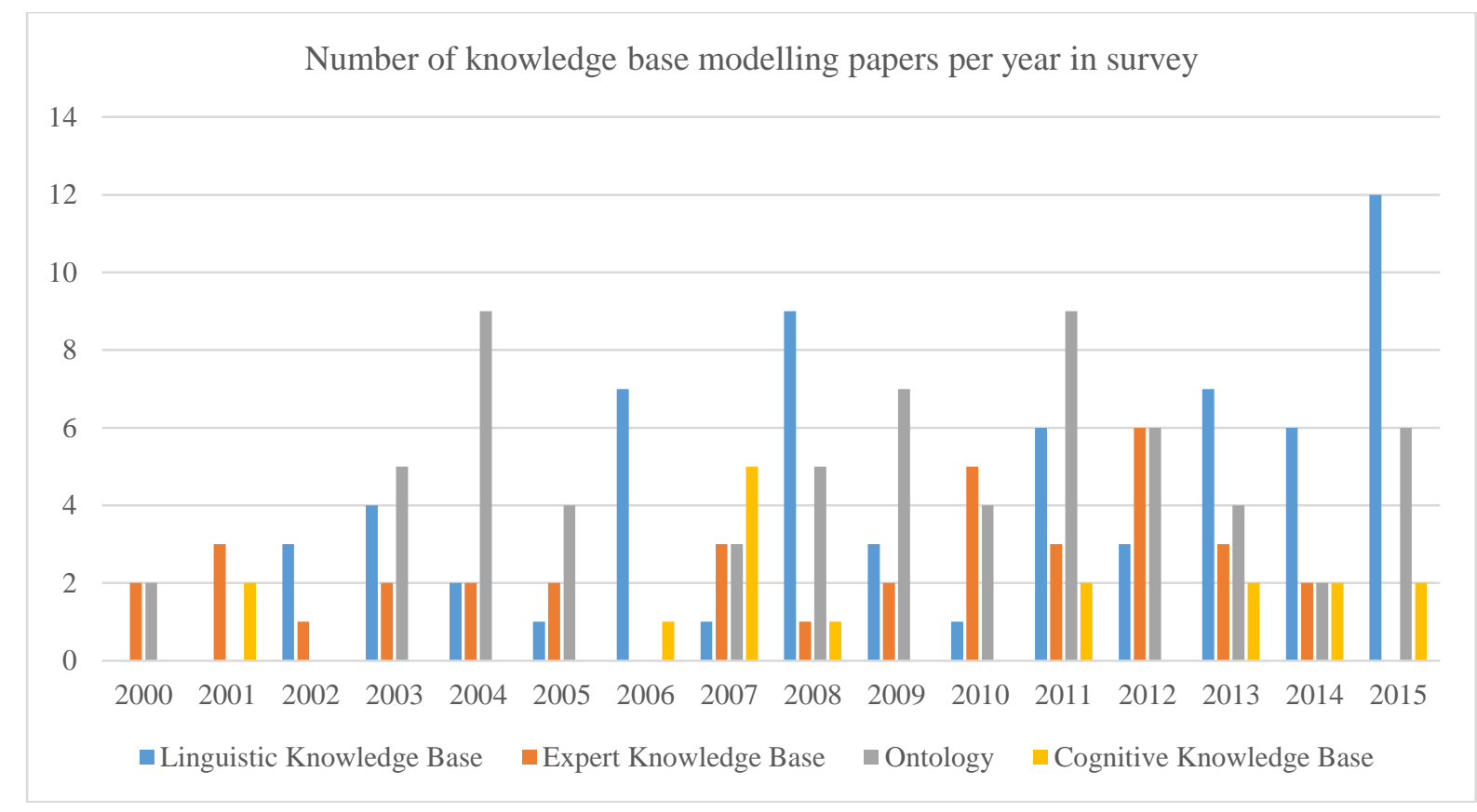

Figure 3 Number of knowledge base modelling articles per year in survey

Based on our survey, from the year 2000 to 2015, linguistic knowledge base and ontology are more often used for representing knowledge, as compared to expert and cognitive knowledge bases. Cognitive knowledge base is relatively new, and has the least number of publications from the year 2000 to 2015 in comparison with other 
knowledge base technologies. Currently, there are more implementations of linguistic knowledge bases. This could be as a result of the increase in mobile gadgets, resulting in the need for more text analysis and information retrieval.

\subsection{Comparison of Knowledge Base Modelling Approaches}

Based on the knowledge base modelling approaches identified, a comparison is made according to their underlying theories, knowledge representation technique, knowledge acquisition technique and challenges. A detail of this comparison is presented in Table 2 . The main objective is to identify and compare the various ways in which knowledge is acquired and represented by each knowledge base modelling approach. The limitations of each approach are highlighted, and possible solutions are discussed.

Table 2 Comparison of Knowledge Base Modelling Approaches

\begin{tabular}{|c|c|c|c|c|c|}
\hline $\begin{array}{l}\text { Knowledge } \\
\text { Base } \\
\text { Technology }\end{array}$ & Theory & Structure & $\begin{array}{l}\text { Knowledge } \\
\text { Representation }\end{array}$ & $\begin{array}{l}\text { Knowledge } \\
\text { Acquisition }\end{array}$ & Limitations \\
\hline $\begin{array}{l}\text { Linguistic } \\
\text { Knowledge } \\
\text { Base }\end{array}$ & $\begin{array}{l}\text { Frame } \\
\text { semantics, } \\
\text { common } \\
\text { sense } \\
\text { knowledge } \\
\text { and word } \\
\text { association } \\
\text { norms }\end{array}$ & $\begin{array}{l}\text { Frames, } \\
\text { lexical } \\
\text { semantic } \\
\text { associations } \\
\text { between } \\
\text { synsets and } \\
\text { graph }\end{array}$ & $\begin{array}{l}\text { Frame elements, } \\
\text { semantic } \\
\text { network and } \\
\text { semantic graph }\end{array}$ & $\begin{array}{l}\text { Mostly manual, } \\
\text { with some } \\
\text { Automated } \\
\text { methods such as } \\
\text { LSPE and } \\
\text { acquiring English } \\
\text { sentences from } \\
\text { the OMCS corpus }\end{array}$ & $\begin{array}{l}\text { 1. Dependence on } \\
\text { volatile expert } \\
\text { knowledge. } \\
\text { 2. Difficult and } \\
\text { expensive to } \\
\text { build and } \\
\text { expand, while } \\
\text { preserving the } \\
\text { richness of its } \\
\text { annotations. } \\
\text { 3. CN has shallow } \\
\text { knowledge } \\
\text { coverage } \\
\text { compared to } \\
\text { human } \\
\text { knowledge. } \\
\text { 4. FN cannot } \\
\text { handle text } \\
\text { coherence } \\
\text { 5. WN has } \\
\text { exceedingly fine } \\
\text { granularity of } \\
\text { senses. } \\
\text { 6. WN has } \\
\text { connotation } \\
\text { inconsistencies. } \\
\text { 7. FN cannot link } \\
\text { arguments across } \\
\text { sentences. }\end{array}$ \\
\hline $\begin{array}{l}\text { Expert } \\
\text { Knowledge } \\
\text { Base }\end{array}$ & $\begin{array}{l}\text { Binary Logic } \\
\text { and fuzzy set }\end{array}$ & $\begin{array}{l}\text { Linguistic } \\
\text { object, value } \\
\text { and operator }\end{array}$ & IF THEN rules & $\begin{array}{l}\text { Commonly a } \\
\text { manual process } \\
\text { where knowledge } \\
\text { is acquired from } \\
\text { domain experts } \\
\text { who communicate }\end{array}$ & $\begin{array}{l}\text { 1. Difficulty in } \\
\text { capturing expert } \\
\text { knowledge. } \\
\text { 2. Brittleness of } \\
\text { rules. }\end{array}$ \\
\hline
\end{tabular}




\begin{tabular}{|c|c|c|c|c|c|}
\hline $\begin{array}{l}\text { Knowledge } \\
\text { Base } \\
\text { Technology }\end{array}$ & Theory & Structure & $\begin{array}{l}\text { Knowledge } \\
\text { Representation }\end{array}$ & $\begin{array}{l}\text { Knowledge } \\
\text { Acquisition }\end{array}$ & Limitations \\
\hline & & & & $\begin{array}{l}\text { their knowledge, } \\
\text { through } \\
\text { questionnaires } \\
\text { and interviews. It } \\
\text { could also be } \\
\text { data-driven. }\end{array}$ & $\begin{array}{l}\text { 3. Difficulty } \\
\text { maintain large } \\
\text { rule-base. } \\
\text { 4. Inference } \\
\text { efficiency } \\
\text { problem. }\end{array}$ \\
\hline Ontology & $\begin{array}{l}\text { Nature of } \\
\text { being }\end{array}$ & $\begin{array}{l}\text { Classes, } \\
\text { relations and } \\
\text { instances }\end{array}$ & $\begin{array}{l}\text { Taxonomy of } \\
\text { concepts with } \\
\text { their attributes, } \\
\text { values and } \\
\text { relations }\end{array}$ & $\begin{array}{l}\text { Frequently } \\
\text { acquired manually } \\
\text { from knowledge } \\
\text { engineers or } \\
\text { domain experts. } \\
\text { Could also be } \\
\text { data-driven by } \\
\text { extracting data } \\
\text { from web } \\
\text { documents, } \\
\text { dictionaries and } \\
\text { database schemas. }\end{array}$ & $\begin{array}{l}\text { 1. Difficulty in } \\
\text { capturing expert } \\
\text { knowledge } \\
\text { 2. Lack of } \\
\text { sufficiently } \\
\text { validated and } \\
\text { generalized } \\
\text { development } \\
\text { methodology }\end{array}$ \\
\hline $\begin{array}{l}\text { Cognitive } \\
\text { Knowledge } \\
\text { Base }\end{array}$ & $\begin{array}{l}\text { Concept as } \\
\text { the } \\
\text { fundamental } \\
\text { unit of } \\
\text { human } \\
\text { knowledge }\end{array}$ & $\begin{array}{l}\text { Consist of } \\
\text { the logical } \\
\text { model, } \\
\text { physical } \\
\text { model, } \\
\text { linguistic } \\
\text { knowledge } \\
\text { base and } \\
\text { knowledge } \\
\text { manipulation } \\
\text { engine. }\end{array}$ & $\begin{array}{l}\text { Object-attribute- } \\
\text { relation (OAR) } \\
\text { model based on } \\
\text { concept algebra }\end{array}$ & $\begin{array}{l}\text { Fully automated } \\
\text { processes of } \\
\text { concept } \\
\text { memorization and } \\
\text { knowledge fusion, } \\
\text { similar to human } \\
\text { and cognitive } \\
\text { systems learning } \\
\text { processes }\end{array}$ & $\begin{array}{l}\text { Fewer development } \\
\text { tools and } \\
\text { implementations in } \\
\text { comparison with } \\
\text { other knowledge } \\
\text { representation } \\
\text { technologies }\end{array}$ \\
\hline
\end{tabular}

Based on the structure of the various categories compared, the cognitive knowledge base structure consists of a combination of the structure of the other three categories. It has a logical model, a linguistic knowledge base and an object-attribute-relation which is similar to attribute, values and relations of concepts in an ontology. Knowledge acquisition in a cognitive knowledge base is fully automated, unlike ontologies, expert knowledge base and linguistic knowledge base. For this reason, the cognitive knowledge base can be more suitable for developing applications where manual knowledge elicitation is cumbersome and costly. Unlike the cognitive knowledge base, linguistic knowledge base, expert knowledge base and ontology depend highly on volatile expert knowledge.

\subsection{Evaluation of Knowledge Base Application Categories}

We examined 72 articles related to various applications of knowledge base models. As a result, we identified 14 different application categories which are Natural Language Processing (NLP), Question Answering (QA), Information Extraction (IE) / Information Retrieval (IR), Classification, Knowledge Discovery (KD), Engineering, Health Care, Education, Finance, Environment, Business, Machine Learning, Robotics and Forecasting. In figure 4 the knowledge base applications versus the knowledge base modelling categories are presented. The main aim is to identify suitable applications of each knowledge base modelling approach. 


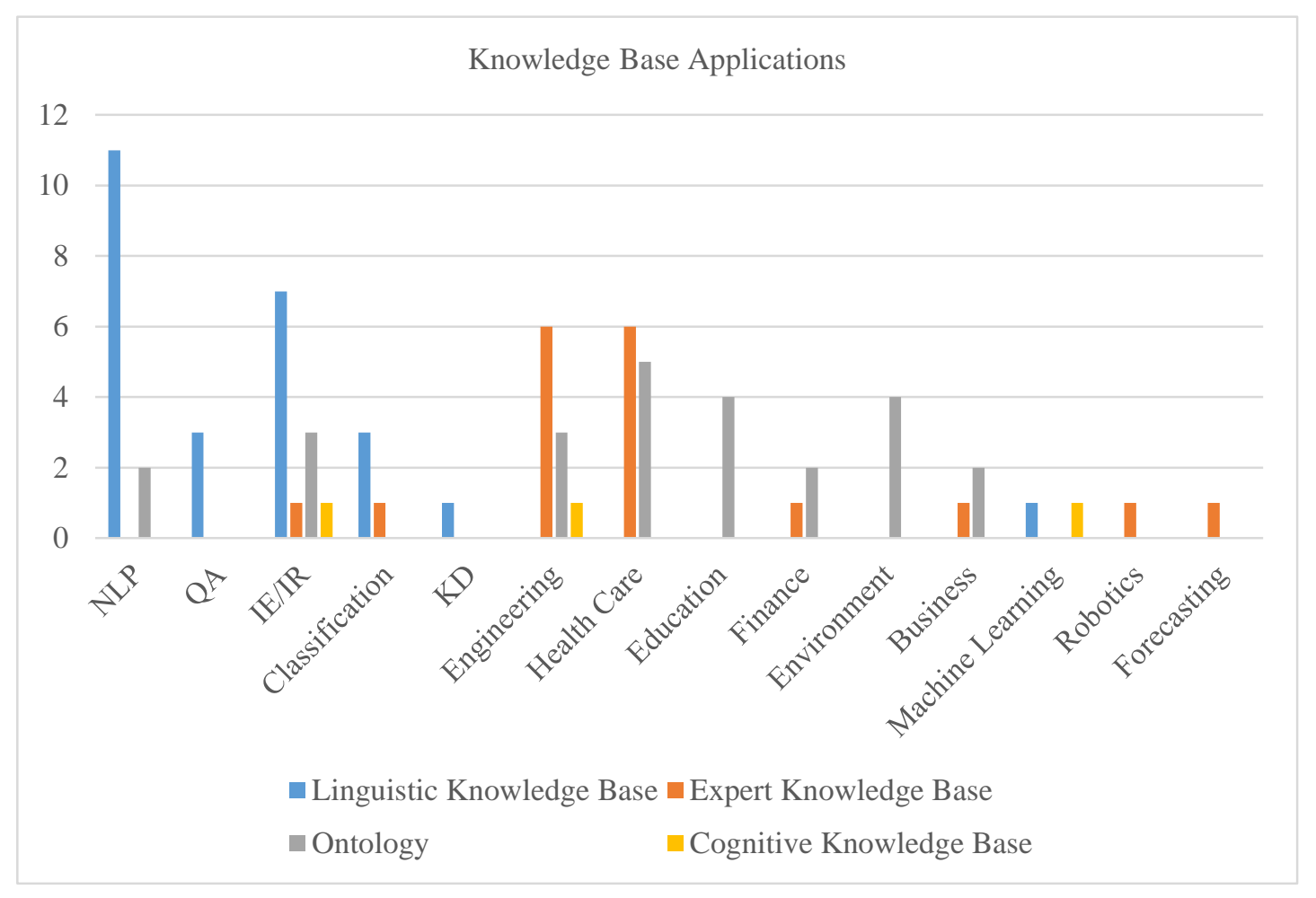

Figure 4 Knowledge Base Applications

Evidently, the linguistic knowledge base is mostly suitable for natural language processing, information retrieval and extraction. Expert knowledge base are mostly applied in engineering and health care domains. Based on our survey, ontologies are the only modelling approach used in education and environmental fields. While the cognitive knowledge base is used for machine learning.

\subsection{Evaluation of Knowledge Base Implementation Tools}

In this survey, various knowledge base implementation tools were identified from 32 different articles. The 19 tools identified across the 4 categories of knowledgebase modelling techniques are represented in figure 5. The main purpose is to identify the commonly used development tool by each modelling technique. 


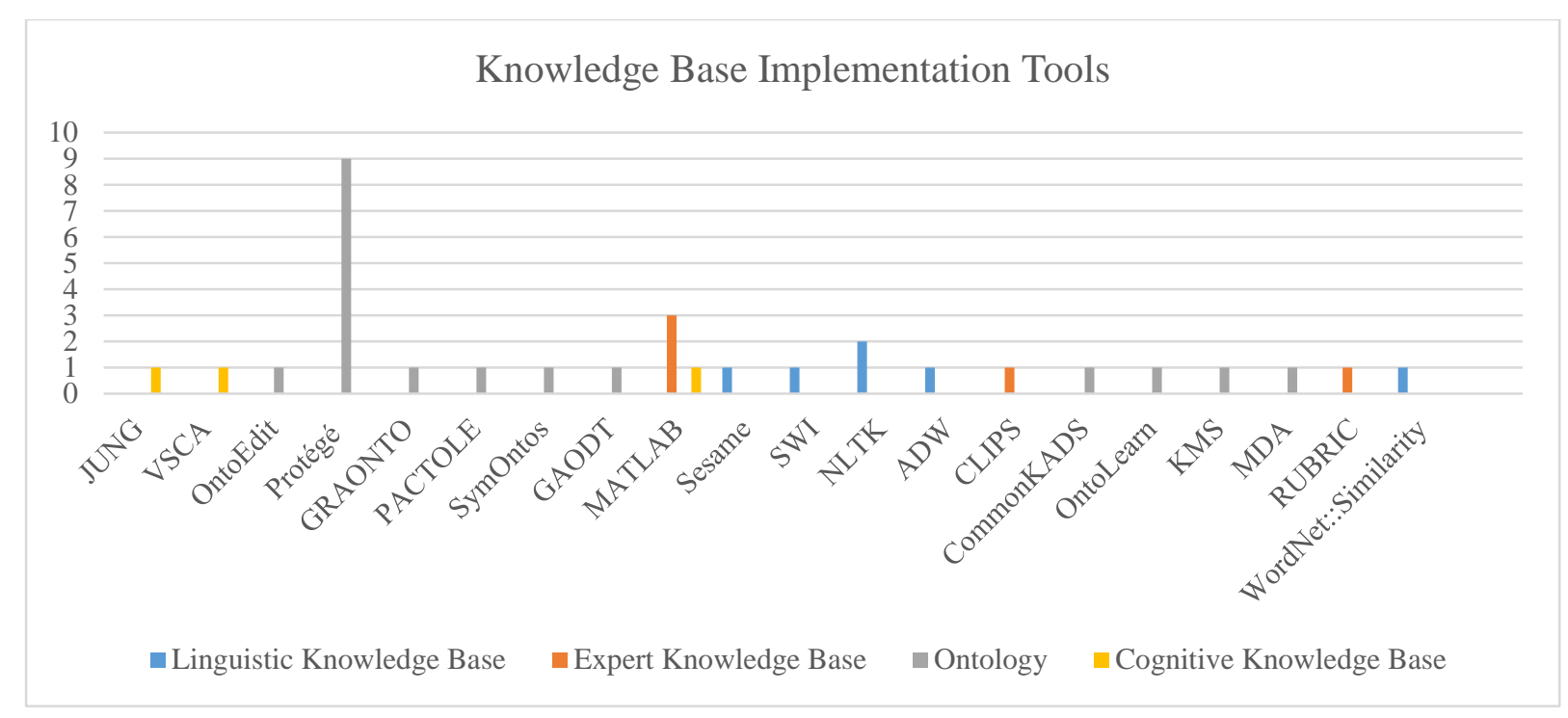

Figure 5 Knowledge Base Implementation Tools

Protégé is the most common tool used in ontology development. It is popularly used because of its extensible plug and play development environment, which supports rapid prototyping and application development. Subsequently, it can be exported in a variety of formats such as, RDF, RDFS, OWL and XML schema. While MATLAB is mostly used for expert knowledge base implementation. MATLAB provides a natural way to express rules, its built-in graphics makes it easy to visualize and understand data.

\subsection{Evaluation on Programming Language}

Several programming languages are used in developing knowledge base models. We identified 9 different languages from 26 related articles in this survey. Figure 6 represents the development languages based on the knowledge base modelling categories. The goal is to identify the various programming languages used by each modelling approach. 
12

10

8

6

4

2

0

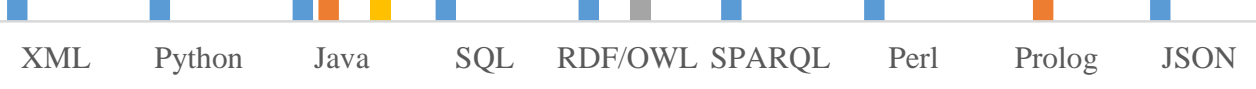

घinguistic Knowledge Base $₫$ Expert Knowledge Base $₫$ Ontology $\square$ Cognitive Knowledge Base

Figure 6 Knowledge Base Programming Languages

A wider range of programming languages are used in linguistic knowledge base development in comparison with the other knowledge base technologies. This reflects the complexity in capturing human lexical knowledge. Most ontologies are developed using RDF/OWL, because it facilitates better machine interpretability of information content.

\subsection{Knowledge-Based Business}

Currently, organizing knowledge as well as knowledge manipulation activities and tools are of great interest among businesses and scientist. Similar to business process management, knowledge management methods and tools are necessary for optimization, automation, formalization and management of knowledge activities within organisations (Chang, 2015). The next growth in economic business is envisaged to come from knowledge-based businesses. Similar to other applications of knowledge base modelling and manipulation technologies, businesses need to know what the customer requires and need in advance. In order, to accomplish this requirements, businesses have to continually monitor news, economic activities, conduct surveys, acquire feedback from their customers, monitor social media to understand the needs of their customers (Yaqoob et al., 2016). With the introduction of big data, many business enterprises have devised ways and techniques to offer products that meet customer expectations (Chang et al., 2016). All this information has to be organised to provide the necessary knowledge to move the business forward.

Existing business modelling methods are concerned with modelling knowledge manipulation activities and its connection to business processes, not considering knowledge management and its relationship with business management processes. Based on the 4 categories of knowledge modelling and manipulation technologies considered, expert systems and ontologies are mostly applied to business management processes. Generic ontologies provide the means to define state, event, process, action and components involved in business management. For example, TOGAF contains knowledge about business management processes of an enterprise. Similarly, the expert knowledge base has been applied economic analysis product orders (Ustundag et al., 2010). However, all these techniques are faced with crucial challenges of knowledge acquisition. The brittleness of rule and the difficulty in maintaining a large rule-based system makes this technique less effective for capturing the knowledge required to provide customers with the required products. Although ontologies prove to be useful in business management, challenges are encountered in knowledge acquisition. The process of building ontologies 
is quite cumbersome. The solution to these limitations is through the application of an automated knowledge acquisition process, which is dynamic and adaptable to customer's changing needs.

Future Directions

Cognitive knowledge base, a recent knowledge base modelling and manipulation technique which models data based on the fundamental unit of human knowledge, provides a promising approach to knowledge-based business management and other knowledge related applications. Its advantage can be seen from its structure which involves a logical model, linguistic knowledge base and an object-attribute relationship similar to ontologies. Acquiring knowledge using this technique is fully automated, thereby eliminating this cumbersome process, which is common to other techniques. Since the cognitive knowledge base acquires knowledge in the same way as the human, it provides a means to better emulate the customer needs. Its dynamic nature makes it ideal for accommodating the changing needs of customers.

\section{Survey Limitations}

A literature review focusing on a broader aspect of knowledge modelling and manipulation technologies is a tough task based on the requirement for extensive background knowledge. Even though limited in background knowledge, this article presents a brief survey of knowledge base modelling and manipulation technologies from 2000-2015. Conforming to this duration has led to the exclusion of well-known application of knowledge base technology such as MYCIN (Buchanan, 1984) a rule-based expert system for diagnosis of infectious blood diseases. And the KADs (Wielinga, 1992) a common knowledge acquisition technique. Although, we reviewed 185 articles, we could only have access to subscribed journals, thus possibly omitting relevant articles from unsubscribed journals. In order to reduce complexity, we focused on only 4 digital libraries, hence neglecting databases such as google scholar and SAGE. Non-English publications are also not included in this survey. We suggest that further research should be done to provide a detailed review of each category of knowledge base modelling and manipulation technology presented in this survey.

\section{Conclusion}

This survey focused on publications related to knowledge base modelling and manipulation technologies, between year 2000 and 2015. The main aim of the research is to identify different knowledge base modelling and manipulation techniques based on 4 categories; linguistic knowledge base, expert knowledge base, ontology and cognitive knowledge base. This led to the proposition of 8 research questions. The questions focused on the different categories of knowledge base modelling technologies, their underlying theories, knowledge representation technique, knowledge acquisition technique, challenges, applications, development tools and development languages. Based on the results obtained, the linguistic knowledge base, expert knowledge base and ontology depend mostly on volatile expert knowledge. We observed that the cognitive knowledge base least number of publications from year 2000 to 2015 in comparison with other knowledge base technologies. Linguistic knowledge base technologies are obviously well applied in NLP, IE and IR as seen from the results in figure 4. Expert knowledge base and Ontology cover a wider range of applications as compared to linguistic and cognitive knowledge bases. Protégé is the most common tool used in ontology development, while MATLAB is mostly used for expert knowledge base implementation. RDF/OWL language is frequently, used in ontology development. A wider range of programming languages are used in linguistic knowledge base development in comparison with the other knowledge base technologies. Our survey reveals the various underlying theories, knowledge representation technique, knowledge acquisition technique, challenges, applications, development tools and development languages of a broad category of knowledge base technologies. This could provide business owners with techniques to relate knowledge management and business management processes. It also provides novice researchers with a tool to select appropriate knowledge representation and implementation techniques, while providing experts with a broader view for introducing novel techniques.

Funding: This work was supported by the University of Malaya Research Grant [RP040B-15AET, 2015] 


\section{References}

Adriaenssens, V., De Baets, B., Goethals, P. L. M., \& De Pauw, N. (2004). Fuzzy rule-based models for decision support in ecosystem management. Science of the Total Environment, 319(1-3), 1-12. doi: 10.1016/S0048-9697(03)00433-9

Agarwal, B., Mittal, N., Bansal, P., \& Garg, S. (2015). Sentiment analysis using common-sense and context information. Computational Intelligence and Neuroscience, 2015. doi: 10.1155/2015/715730

Agarwal, B., Poria, S., Mittal, N., Gelbukh, A., \& Hussain, A. (2015). Concept-Level Sentiment Analysis with Dependency-Based Semantic Parsing: A Novel Approach. Cognitive Computation, 7(4), 487-499. doi: 10.1007/s12559-014-9316-6

Akkermans, H., Baida, Z., Gordijn, J., Peiia, N., Altuna, A., \& Laresgoiti, I. (2004). Value Webs: using ontologies to bundle real-world services. Ieee Intelligent Systems, 19(4), 57-66. doi: 10.1109/MIS.2004.35

Al-Safadi, L. A. E., \& Al-Abdullatif, N. A. O. (2010). Educational advertising ontology: A domain-dependent ontology for semantic advertising networks. Journal of Computer Science, 6(10), 1070-1077. doi: 10.3844/jcssp.2010.1070.1077

Apisakmontri, P., Nantajeewarawat, E., Ikeda, M., \& Buranarach, M. (2016). An ontology-based framework for semantic reconciliation in humanitarian aid in Emergency information systems. Journal of Information Processing, 24(1), 73-82. doi: 10.2197/ipsijip.24.73

Assali, A. A., Lenne, D., \& Debray, B. (2007, 3-7 Sept. 2007). KoMIS: An Ontology-Based Knowledge Management System for Industrial Safety. Paper presented at the Database and Expert Systems Applications, 2007. DEXA '07. 18th International Workshop on.

Bai, Y., Zhuang, H., \& Roth, Z. S. (2005). Fuzzy logic control to suppress noises and coupling effects in a laser tracking system. Control Systems Technology, IEEE Transactions on, 13(1), 113-121.

Baker, C. F. (2012). FrameNet, current collaborations and future goals. Language Resources and Evaluation, 46(2), 269-286. doi: 10.1007/s10579-012-9191-2

Baker, C. F. (2014). FrameNet: A Knowledge Base for Natural Language Processing. Paper presented at the Proceedings of Frame Semantics in NLP: A Workshop in Honor of Chuck Fillmore.

Banerjee, J. S., Jones, K. O., \& Williams, D. (2001). Design considerations for a model reference fuzzy adaptive controller. Transactions of the Institute of Measurement and Control, 23(3), 141-162.

Batet, M., Sanchez, D., \& Valls, A. (2011). An ontology-based measure to compute semantic similarity in biomedicine. Journal of Biomedical Informatics, 44(1), 118-125.

Baydin, A. G., López de Mántaras, R., \& Ontañón, S. (2015). A semantic network-based evolutionary algorithm for computational creativity. Evolutionary Intelligence, 8(1), 3-21. doi: 10.1007/s12065-014-0119-1

Bendaoud, R., Toussaint, Y., \& Napoli, A. (2008) PACTOLE: A methodology and a system for semiautomatically enriching an ontology from a collection of texts. Vol. 5113 LNAI. Lecture Notes in Computer Science (including subseries Lecture Notes in Artificial Intelligence and Lecture Notes in Bioinformatics) (pp. 203-216).

Benslimane, S. M., Bensaber, D. A., \& Malki, M. (2005, 2005). Towards a multi-representation ontology-based information systems mediation. Paper presented at the Computer Systems and Applications, 2005. The 3rd ACS/IEEE International Conference on.

Bicocchi, N., Castelli, G., Mamei, M., \& Zambonelli, F. (2011) Augmenting mobile localization with activities and common sense knowledge. Vol. 7040 LNCS. Lecture Notes in Computer Science (including subseries Lecture Notes in Artificial Intelligence and Lecture Notes in Bioinformatics) (pp. 72-81).

Bird, S. (2006). NLTK: the natural language toolkit. Paper presented at the Proceedings of the COLING/ACL on Interactive presentation sessions.

Boas, H. C. (2005). Semantic frames as interlingual representations for multilingual lexical databases. International journal of lexicography, 18(4), 445-478. doi: 10.1093/ij1/eci043

Bombardier, V., Mazaud, C., Lhoste, P., \& Vogrig, R. (2007). Contribution of fuzzy reasoning method to knowledge integration in a defect recognition system. Computers in Industry, 58(4), 355-366.

Borst, W. N. (1997). Construction of engineering ontologies for knowledge sharing and reuse: Universiteit Twente.

Boyacioglu, M. A., \& Avci, D. (2010). An adaptive network-based fuzzy inference system (ANFIS) for the prediction of stock market return: the case of the Istanbul stock exchange. Expert Systems with Applications, 37(12), 7908-7912. 
Brenga, C., Celotto, A., Loia, V., \& Senatore, S. (2015, 20-22 Nov. 2015). SentiWordSKOS: A lexical ontology extended with sentiments and emotions. Paper presented at the 2015 Conference on Technologies and Applications of Artificial Intelligence (TAAI).

Bright, T. J., Furuya, E. Y., Kuperman, G. J., Cimino, J. J., \& Bakken, S. (2012). Development and evaluation of an ontology for guiding appropriate antibiotic prescribing. Journal of Biomedical Informatics, 45(1), $120-128$

Broekstra, J., Kampman, A., \& Van Harmelen, F. (2003). Sesame: An architecture for storing and querying RDF data and schema information. Spinning the Semantic Web: Bringing the World Wide Web to Its Full Potential, 197.

Capella, J. V., Bonastre, A., \& Ors, R. (2003, 16-19 Sept. 2003). A bridge crane advanced control system implemented by means of a distributed expert system. Paper presented at the Emerging Technologies and Factory Automation, 2003. Proceedings. ETFA '03. IEEE Conference.

Castilho, L. V., Lopes, H. S., \& Tacla, C. A. (2008, 10-12 Sept. 2008). Modeling and Building an Ontology for Neuropediatric Physiotherapy Domain. Paper presented at the Hybrid Intelligent Systems, 2008. HIS '08. Eighth International Conference on.

Ceccaroni, L., Cortes, U., \& Sanchez-Marre, M. (2004). OntoWEDSS: augmenting environmental decisionsupport systems with ontologies. Environmental Modelling \& Software, 19(9), 785-797.

Celikyilmaz, A., \& Turksen, I. B. (2008). Enhanced fuzzy system models with improved fuzzy clustering algorithm. Ieee Transactions on Fuzzy Systems, 16(3), 779-794.

Chang, V. (2015). A Proposed Cloud Computing Business Framework. Nova Science Publisher.

Chan, C. W. (2004a, 2-5 May 2004). The Knowledge Modeling System and its application. Paper presented at the Electrical and Computer Engineering, 2004. Canadian Conference on.

Chan, C. W. (2004b, 16-17 Aug. 2004). Towards ontology construction for an industrial domain. Paper presented at the Cognitive Informatics, 2004. Proceedings of the Third IEEE International Conference on.

Chen, H., Finin, T., \& Joshi, A. (2003). An ontology for context-aware pervasive computing environments. The Knowledge Engineering Review, 18(03), 197-207.

Chen, L., Nugent, C., Mulvenna, M., Finlay, D., \& Hong, X. (2009). Semantic smart homes: towards knowledge rich assisted living environments Intelligent Patient Management (pp. 279-296): Springer.

Chen, R. C., Liang, J. Y., \& Pan, R. H. (2008). Using recursive ART network to construction domain ontology based on term frequency and inverse document frequency. Expert Systems with Applications, 34(1), 488-501.

Connaghan, D., Moran, K., \& O’Connor, N. E. (2013). An automatic visual analysis system for tennis. Proceedings of the Institution of Mechanical Engineers, Part P: Journal of Sports Engineering and Technology, 227(4), 273-288. doi: 10.1177/1754337112469330

Cordón, O. (2011). A historical review of evolutionary learning methods for Mamdani-type fuzzy rule-based systems: Designing interpretable genetic fuzzy systems. International Journal of Approximate Reasoning, 52(6), 894-913.

Croce, D., \& Basili, R. (2011) Structured learning for semantic role labeling. Vol. 6934 LNAI. Lecture Notes in Computer Science (including subseries Lecture Notes in Artificial Intelligence and Lecture Notes in Bioinformatics) (pp. 238-249).

Czarnecki, A., \& Orłowski, C. (2010) Ontology as a tool for the IT management standards support. Vol. 6071 LNAI. Lecture Notes in Computer Science (including subseries Lecture Notes in Artificial Intelligence and Lecture Notes in Bioinformatics) (pp. 330-339).

Darmoul, S., Pierreval, H., \& Hajri-Gabouj, S. (2011, 5-9 Sept. 2011). Using ontologies to capture and structure knowledge about disruptions in manufacturing systems: An immune driven approach. Paper presented at the Emerging Technologies \& Factory Automation (ETFA), 2011 IEEE 16th Conference on.

Das, D., Chen, D., Andr, \#233, Martins, F. T., Schneider, N., \& Smith, N. A. (2014). Frame-semantic parsing. Computational Linguistics, 40(1), 9-56. doi: 10.1162/COLI_a_00163

Dimitroula, V., Bassiliades, N., Vlahavas, I., \& Dimitrakos, S. (2001). FUNAGES: an expert system for fundus fluorescein angiography. Health Informatics Journal, 7(3-4), 214-221. doi: $10.1177 / 146045820100700317$ 
Dragoni, M., Tettamanzi, A. G. B., \& da Costa Pereira, C. (2015). Propagating and Aggregating Fuzzy Polarities for Concept-Level Sentiment Analysis. Cognitive Computation, 7(2), 186-197. doi: 10.1007/s12559-014-9308-6

Driankov, D., Hellendoorn, H., \& Reinfrank, M. (2013). An introduction to fuzzy control: Springer Science \& Business Media.

Duan, H., Wu, S., \& Ye, F. (2013, 20-23 Aug. 2013). The Application of the Knowledge Representation Based on Concept Algebra in the Knowledge Management System of Petroleum Enterprise. Paper presented at the Green Computing and Communications (GreenCom), 2013 IEEE and Internet of Things (iThings/CPSCom), IEEE International Conference on and IEEE Cyber, Physical and Social Computing.

Duch, W., Adamczak, R., \& Grạbczewski, K. (2001). A new methodology of extraction, optimization and application of crisp and fuzzy logical rules. Ieee Transactions on Neural Networks, 12(2), 277-306. doi: $10.1109 / 72.914524$

Durbha, S. S., \& King, R. L. (2004, 20-24 Sept. 2004). Knowledge mining in Earth observation data archives: a domain ontology perspective. Paper presented at the Geoscience and Remote Sensing Symposium, 2004. IGARSS '04. Proceedings. 2004 IEEE International.

Durbha, S. S., King, R. L., Shah, V. P., \& Younan, N. H. (2009). A framework for semantic reconciliation of disparate earth observation thematic data. Computers \& Geosciences, 35(4), 761-773.

Dutra, M., Ghodous, P., Kuhn, O., \& Tri, N. M. (2010). A generic and synchronous ontology-based architecture for collaborative design. Concurrent Engineering Research and Applications, 18(1), 65-74. doi: $10.1177 / 1063293 X 10361622$

Ebrahimipour, V., \& Yacout, S. (2015). Ontology-Based Schema to Support Maintenance Knowledge Representation With a Case Study of a Pneumatic Valve. IEEE Transactions on Systems, Man, and Cybernetics: Systems, 45(4), 702-712. doi: 10.1109/TSMC.2014.2383361

El-Diraby, T. E., \& Osman, H. (2011). A domain ontology for construction concepts in urban infrastructure products. Automation in Construction, 20(8), 1120-1132. doi: 10.1016/j.autcon.2011.04.014

El-Subaihi, J. A., Anton, F., Mioc, D., Andersen, S. V., \& Lausen, B. (2013). Child cancer follow-up ontology and information system. Paper presented at the WIT Transactions on Information and Communication Technologies.

El Kharbili, M., \& Stolarski, P. (2009) Building-up a reference generic regulation ontology: A bottom-up approach. Vol. 37 LNBIP. Lecture Notes in Business Information Processing (pp. 268-279).

Erjavec, T., \& Fišer, D. (2006). Building the Slovene Wordnet: first steps, first problems. Paper presented at the Proceedings of the Third International WordNet Conference-GWC.

Erk, K., \& Pado, S. (2006). Shalmaneser-a flexible toolbox for semantic role assignment. Paper presented at the Proceedings of LREC.

Fadaee, M., Ghader, H., Faili, H., \& Shakery, A. (2013). Automatic WordNet Construction Using Markov Chain Monte Carlo. Polibits, 47, 13-22.

Fay, A. (2000). A fuzzy knowledge-based system for railway traffic control. Engineering Applications of Artificial Intelligence, 13(6), 719-729.

Feilmayr, C., \& Wöß, W. (2016). An analysis of ontologies and their success factors for application to business. Data and Knowledge Engineering, 101, 1-23. doi: 10.1016/j.datak.2015.11.003

Fellbaum, C. (1998). WordNet: Wiley Online Library.

Fellbaum, C., Hahn, U., \& Smith, B. (2006). Towards new information resources for public health-from WordNet to MedicalWordNet. Journal of Biomedical Informatics, 39(3), 321-332.

Fensel, D. (2004). Ontologies A Silver Bullet for Knowledge Management and Electronic Commerce (Second Edition, Revised and Extended. ed.). Berlin, Heidelberg: Springer Berlin Heidelberg :.

Fernandez, A., del Jesus, M. J., \& Herrera, F. (2010). On the 2-tuples based genetic tuning performance for fuzzy rule based classification systems in imbalanced data-sets. Information Sciences, 180(8), 12681291.

Fillmore, C. J., Johnson, C. R., \& Petruck, M. R. L. (2003). Background to framenet. International journal of lexicography, 16(3), 235-250. doi: 10.1093/ij1/16.3.235

Freitas, A., Da Silva, J. C. P., Curry, E., \& Buitelaar, P. (2015). Approximate and selective reasoning on knowledge graphs: A distributional semantics approach. Data and Knowledge Engineering, 100, 211225. doi: 10.1016/j.datak.2015.06.010 
Garrette, D., \& Klein, E. (2009). An extensible toolkit for computational semantics. Paper presented at the Proceedings of the Eighth International Conference on Computational Semantics.

Giannone, C. (2013) Generative and discriminative learning in semantic role labeling for Italian. Vol. 7689 LNAI. Lecture Notes in Computer Science (including subseries Lecture Notes in Artificial Intelligence and Lecture Notes in Bioinformatics) (pp. 212-219).

Gil, R., Virgili-Gomá, J., García, R., \& Mason, C. (2015). Emotions ontology for collaborative modelling and learning of emotional responses. Computers in Human Behavior. doi: 10.1016/j.chb.2014.11.100

Gildea, D., \& Jurafsky, D. (2002). Automatic labeling of semantic roles. Computational Linguistics, $28(3)$, 245 288. doi: 10.1162/089120102760275983

Grassi, M., \& Piazza, F. (2011) Towards an RDF encoding of ConceptNet. Vol. 6677 LNCS. Lecture Notes in Computer Science (including subseries Lecture Notes in Artificial Intelligence and Lecture Notes in Bioinformatics) (pp. 558-565).

Gruzitis, N., \& Dannélls, D. (2015). A multilingual FrameNet-based grammar and lexicon for controlled natural language. Language Resources and Evaluation. doi: 10.1007/s10579-015-9321-8

Guimaraes, A. C. F., \& Lapa, C. M. F. (2007). Fuzzy inference to risk assessment on nuclear engineering systems. Applied Soft Computing, 7(1), 17-28.

Hampton, J. A. (1997). Psychological representation of concepts. Cognitive models of memory, 81-110.

Hou, X., Ong, S. K., Nee, A. Y. C., Zhang, X. T., \& Liu, W. J. (2011). GRAONTO: A graph-based approach for automatic construction of domain ontology. Expert Systems with Applications, 38(9), 11958-11975.

Hsu, M.-H., Tsai, M.-F., \& Chen, H.-H. (2006). Query expansion with conceptnet and wordnet: An intrinsic comparison Information Retrieval Technology (pp. 1-13): Springer.

Hsu, M. H., Tsai, M. F., \& Chen, H. H. (2008) Combining WordNet and ConceptNet for automatic query expansion: A learning approach. Vol. 4993 LNCS. Lecture Notes in Computer Science (including subseries Lecture Notes in Artificial Intelligence and Lecture Notes in Bioinformatics) (pp. 213-224).

Hu, K., \& Wang, Y. (2007a, 22-26 April 2007). Applying Concept Algebra to Information Restructuring of Web Documents. Paper presented at the Electrical and Computer Engineering, 2007. CCECE 2007. Canadian Conference on.

Hu, K., \& Wang, Y. (2007b, 6-8 Aug. 2007). Autolearner: An Autonomic Machine Learning System Based on Concept Algebra. Paper presented at the Cognitive Informatics, 6th IEEE International Conference on.

$\mathrm{Hu}, \mathrm{K} .$, \& Wang, Y. (2007). A web knowledge discovery engine based on concept algebra. Paper presented at the Electrical and Computer Engineering, 2007. CCECE 2007. Canadian Conference on.

Huang, D., \& Gao, J. (2009, 19-21 May 2009). Technology of Building Domain Ontology Based on SECI. Paper presented at the Software Engineering, 2009. WCSE '09. WRI World Congress on.

Irmer, M. (2013). Inferring implicatures and discourse relations from frame information. Lingua, 132, 29-50. doi: 10.1016/j.lingua.2012.11.009

Jafelice, R. M., Bechara, B. F. Z., Barros, L. C., Bassanezi, R. C., \& Gomide, F. (2009). Cellular automata with fuzzy parameters in microscopic study of positive HIV individuals. Mathematical and Computer Modelling, 50(1-2), 32-44.

Jin Tan, Y., Min Jey, H., \& Yuan Fong, C. (2005, 5-8 July 2005). A study on searching and recommending SCORM CPs by ontological support. Paper presented at the Advanced Learning Technologies, 2005. ICALT 2005. Fifth IEEE International Conference on.

Kerr-Wilson, J., \& Pedrycz, W. (2016). Design of rule-based models through information granulation. Expert Systems with Applications, 46, 274-285.

Kettnerová, V., Lopatková, M., \& Hrstková, K. (2008) Semantic roles in valency lexicon of Czech verbs: Verbs of communication and exchange. Vol. 5221 LNAI. Lecture Notes in Computer Science (including subseries Lecture Notes in Artificial Intelligence and Lecture Notes in Bioinformatics) (pp. 217-221).

Khan, W. A., Amin, M. B., Khattak, A. M., Hussain, M., Afzal, M., Lee, S., \& Kim, E. S. (2015). Objectoriented and ontology-alignment patterns-based expressive Mediation Bridge Ontology (MBO). Journal of Information Science, 41(3), 296-314.

Khan, S., Ilyas Q. M., Anwar W. (2009) Contextual advertising using keyword extraction through collocation. Proceedings of the 7th International Conference on Frontiers of Information Technology. ACM.

Kilinc, D., \& Alpkocak, A. (2011). An expansion and reranking approach for annotation-based image retrieval from Web. Expert Systems with Applications, 38(10), 13121-13127. 
Kimble, C., de Vasconcelos, J. B., \& Rocha, Á. (2016). Competence management in knowledge intensive organizations using consensual knowledge and ontologies. Information Systems Frontiers, 1-12. doi: 10.1007/s10796-016-9627-0

Kohli, D., Sliuzas, R., Kerle, N., \& Stein, A. (2012). An ontology of slums for image-based classification. Computers, Environment and Urban Systems, 36(2), 154-163. doi: 10.1016/j.compenvurbsys.2011.11.001

Kowalski, R., \& Burton, A. (2012) WUENIC - A case study in rule-based knowledge representation and reasoning. Vol. 7258 LNAI. Lecture Notes in Computer Science (including subseries Lecture Notes in Artificial Intelligence and Lecture Notes in Bioinformatics) (pp. 112-125).

Kung, C., \& Su, J. (2007). Affine Takagi-Sugeno fuzzy modelling algorithm by fuzzy c-regression models clustering with a novel cluster validity criterion. IET Control Theory \& Applications, 1(5), 1255-1265.

Labidi, S., \& Sergio, N. (2000, 2000). Student modeling and semi-atutomatic domain ontology construction for SHIECC [atutomatic read automatic]. Paper presented at the Frontiers in Education Conference, 2000. FIE 2000. 30th Annual.

Lahouar, S., Barry Iii, C. E., Paripati, P., Somaiya, S., Huyen, Y., Rosenthal, A., \& Tartakovsky, M. (2012) Automatic extraction and categorization of lung abnormalities from HRCT data in MDR/XDR TB patients. Vol. 145 AISC. Advances in Intelligent and Soft Computing (pp. 351-360).

Lakhfif, A., \& Laskri, M. T. (2015). A frame-based approach for capturing semantics from Arabic text for textto-sign language MT. International Journal of Speech Technology. doi: 10.1007/s10772-015-9290-8

Lee, S., Huh, S.-Y., \& McNiel, R. D. (2008). Automatic generation of concept hierarchies using WordNet. Expert Systems with Applications, 35(3), 1132-1144.

Legaz-García, M. d. C., Miñarro-Giménez, J. A., Madrid, M., Menárguez-Tortosa, M., Torres Martínez, S., \& Fernández-Breis, J. T. (2012). Linking Genome Annotation Projects with Genetic Disorders using Ontologies. Journal of Medical Systems, 1-13. doi: 10.1007/s10916-012-9890-7

Leone, N., Pfeifer, G., Faber, W., Eiter, T., Gottlob, G., Perri, S., \& Scarcello, F. (2006). The DLV system for knowledge representation and reasoning. ACM Transactions on Computational Logic (TOCL), 7(3), 499-562.

Liao, S.-h. (2003). Knowledge management technologies and applications-literature review from 1995 to 2002. Expert Systems with Applications, 25(2), 155-164.

Lin, X., \& Wang, Y. (2014). Simulation and visualization of concept algebra in MATLAB. International Journal of Software Science and Computational Intelligence (IJSSCI), 6(1), 30-55.

Lindén, K., \& Niemi, J. (2014). Is it possible to create a very large wordnet in 100 days? An evaluation. Language Resources and Evaluation, 48(2), 191-201.

Liu, G., Wang, Y., \& Wu, C. (2010). Research and application of geological hazard domain ontology. Paper presented at the Geoinformatics, 2010 18th International Conference on.

Liu, H., Lieberman, H., \& Selker, T. (2002). GOOSE: a goal-oriented search engine with commonsense. Paper presented at the Adaptive Hypermedia and Adaptive Web-Based Systems.

Liu, H., Lieberman, H., \& Selker, T. (2003). A model of textual affect sensing using real-world knowledge. Paper presented at the Proceedings of the 8th international conference on Intelligent user interfaces.

Liu, H., \& Singh, P. (2004). ConceptNet - a practical commonsense reasoning tool-kit. BT technology journal, 22(4), 211-226.

Liu, H. C., Liu, L., Lin, Q. L., \& Liu, N. (2013). Knowledge Acquisition and Representation Using Fuzzy Evidential Reasoning and Dynamic Adaptive Fuzzy Petri Nets. Ieee Transactions on Cybernetics, 43(3), 1059-1072.

López, R. E., Barreda, D., Tejada, J., \& Cuadros, E. (2011) MFSRank: An unsupervised method to extract keyphrases using semantic information. Vol. 7094 LNAI. Lecture Notes in Computer Science (including subseries Lecture Notes in Artificial Intelligence and Lecture Notes in Bioinformatics) (pp. 338-344).

Teófilo, L. F., Reis, L. P., \& Cardoso, H. L. (2014). A Profitable Online No-Limit Poker Playing Agent. Paper presented at the Proceedings of the 2014 IEEE/WIC/ACM International Joint Conferences on Web Intelligence (WI) and Intelligent Agent Technologies (IAT) - Volume 03 (pp. 286-293). IEEE Computy Society.

SAVONNET, M., Leclercq, E., \& Naubourg, P. (2015). eClims: an extensible and dynamic integration framework for biomedical information systems. Ieee Journal of Biomedical and Health Informatics, PP(99), 1-1. doi: 10.1109/JBHI.2015.2464353 
Maalel, A., Mejri, L., Mabrouk, H. H., \& Ben Ghezela, H. (2012). Towards an ontology of help to the modeling of accident scenarii: Application on railroad transport. Paper presented at the 2012 6th International Conference on Sciences of Electronics, Technologies of Information and Telecommunications, SETIT 2012.

Majewski, P., \& Szymański, J. (2008) Text categorization with semantic commonsense knowledge: First results. Vol. 4985 LNCS. Lecture Notes in Computer Science (including subseries Lecture Notes in Artificial Intelligence and Lecture Notes in Bioinformatics) (pp. 769-778).

Makki, J., Alquier, A. M., \& Prince, V. (2008) Semi automatic ontology instantiation in the domain of risk management. Vol. 288. IFIP International Federation for Information Processing (pp. 254-265).

Mansingh, G., Osei-Bryson, K. M., \& Reichgelt, H. (2011). Using ontologies to facilitate post-processing of association rules by domain experts. Information Sciences, 181(3), 419-434.

Marrafa, P. (2002). Portuguese WordNet: general architecture and internal semantic relations. DELTA: Documentação de Estudos em Lingüística Teórica e Aplicada, 18(SPE), 131-146.

Martínez-Santiago, F., Díaz-Galiano, M. C., Ureña-López, L. A., \& Mitkov, R. (2015). A semantic grammar for beginning communicators. Knowledge-Based Systems, 86, 158-172. doi: 10.1016/j.knosys.2015.06.002

Marwat, M. I., Jan, S., Shah, M. A., \& Shah, S. Z. A. (2014). Towards optimization of software engineering ontologies. Paper presented at the 2014 World Congress on Computer Applications and Information Systems, WCCAIS 2014.

Maziarz, M., Piasecki, M., \& Szpakowicz, S. (2013). The chicken-and-egg problem in wordnet design: Synonymy, synsets and constitutive relations. Language Resources and Evaluation, 47(3), 769-796. doi: 10.1007/s10579-012-9209-9

Mena, E., Illarramendi, A., Kashyap, V., \& Sheth, A. P. (2000). OBSERVER: An approach for query processing in global information systems based on interoperation across pre-existing ontologies. Distributed and Parallel Databases, 8(2), 223-271.

Meneses, R., Leite, A., \& Girardi, R. (2015, 17-20 June 2015). Application ontology for the development of case-based intrusion detection systems. Paper presented at the Information Systems and Technologies (CISTI), 2015 10th Iberian Conference on.

Mercantini, J. M., \& Faucher, C. (2012) Building a domain ontology to design a decision support software to plan fight actions against marine pollutions. Vol. 14. Smart Innovation, Systems and Technologies (pp. 83-95).

Mesarić, J., \& Dukić, B. (2007). An approach to creating domain ontologies for higher education in economics. Paper presented at the Proceedings of the International Conference on Information Technology Interfaces, ITI.

Miller, G. A., Beckwith, R., Fellbaum, C., Gross, D., \& Miller, K. J. (1990). Introduction to wordnet: An on-line lexical database*. International journal of lexicography, 3(4), 235-244.

Minkoo, K., Fenghua, L., \& Raghavan, V. V. (2000, 2000). Automatic construction of rule-based trees for conceptual retrieval. Paper presented at the String Processing and Information Retrieval, 2000. SPIRE 2000. Proceedings. Seventh International Symposium on.

Missikoff, M., Velardi, P., \& Fabriani, P. (2003). Text mining techniques to automatically enrich a domain ontology. Applied Intelligence, 18(3), 323-340. doi: 10.1023/A:1023254205945

Mohit, B., \& Narayanan, S. (2003). Semantic extraction with wide-coverage lexical resources. Paper presented at the Proceedings of the 2003 Conference of the North American Chapter of the Association for Computational Linguistics on Human Language Technology: companion volume of the Proceedings of HLT-NAACL 2003--short papers-Volume 2.

Montejo-Raez, A., Martinez-Camara, E., Martin-Valdivia, M. T., \& Urena-Lopez, L. A. (2014). Ranked Word Net graph for Sentiment Polarity Classification in Twitter. Computer Speech and Language, 28(1), 93 107.

Navigli, R. (2013). A quick tour of BabelNet 1.1 Computational Linguistics and Intelligent Text Processing (pp. 25-37): Springer.

Navigli, R., \& Velardi, P. (2004). Learning Domain Ontologies from Document Warehouses and Dedicated Web Sites. Computational Linguistics, 30(2), 151-179. doi: 10.1162/089120104323093276

Negnevitsky, M. (2005). Artificial intelligence: a guide to intelligent systems: Pearson Education.

Noah, S. A., Ali, D. A., Alhadi, A. C., \& Kassim, J. M. (2010) Going beyond the surrounding text to semantically annotate and search digital images. Vol. 5990 LNAI. Lecture Notes in Computer Science 
(including subseries Lecture Notes in Artificial Intelligence and Lecture Notes in Bioinformatics) (pp. 169-179).

Nurnberger, A. (2004). Approximation of dynamic systems using recurrent neuro-fuzzy techniques. Soft Computing, 8(6), 428-442.

O'Hara, T., \& Wiebe, J. (2009). Exploiting semantic role resources for preposition disambiguation. Computational Linguistics, 35(2), 151-184. doi: 10.1162/coli.06-79-prep15

Ochoa, J. L., Valencia-Garcia, R., Perez-Soltero, A., \& Barcelo-Valenzuela, M. (2013). A semantic role labelling-based framework for learning ontologies from Spanish documents. Expert Systems with Applications, 40(6), 2058-2068.

Ofoghi, B., Yearwood, J., \& Ma, L. (2008a) FrameNet-based fact-seeking answer processing: A study of semantic alignment techniques and lexical coverage. Vol. 5360 LNAI. Lecture Notes in Computer Science (including subseries Lecture Notes in Artificial Intelligence and Lecture Notes in Bioinformatics) (pp. 192-201).

Ofoghi, B., Yearwood, J., \& Ma, L. (2008b) The impact of semantic class identification and semantic role labeling on natural language answer extraction. Vol. 4956 LNCS. Lecture Notes in Computer Science (including subseries Lecture Notes in Artificial Intelligence and Lecture Notes in Bioinformatics) (pp. 430-437).

Ozyer, T., Alhajj, R., \& Barker, K. (2007). Intrusion detection by integrating boosting genetic fuzzy classifier and data mining criteria for rule pre-screening. Journal of Network and Computer Applications, 30(1), 99-113.

Padó, S., \& Lapata, M. (2009). Cross-lingual annotation projection of semantic roles. Journal of Artificial Intelligence Research, 36, 307-340. doi: 10.1613/jair.2863

Pandey, B., \& Mishra, R. B. (2009). Knowledge and intelligent computing system in medicine. Computers in Biology and Medicine, 39(3), 215-230.

Park, S. C. (2003). Knowledge capturing methodology in process planning. CAD Computer Aided Design, 35(12), 1109-1117. doi: 10.1016/S0010-4485(02)00182-3

Paul, S., \& Kumar, S. (2002). Subsethood-product fuzzy neural inference system (SuPFuNIS). Ieee Transactions on Neural Networks, 13(3), 578-599. doi: 10.1109/TNN.2002.1000126

Pedersen, T., Patwardhan, S., \& Michelizzi, J. (2004). WordNet:: Similarity: measuring the relatedness of concepts. Paper presented at the Demonstration papers at HLT-NAACL 2004.

Pianta, E., Bentivogli, L., \& Girardi, C. (2002). Developing an aligned multilingual database. Paper presented at the Proc. 1st Int'l Conference on Global WordNet.

Pilehvar, M. T., \& Navigli, R. (2015). An Open-source Framework for Multi-level Semantic Similarity Measurement. Paper presented at the Proceedings of NAACL-HLT.

Pimentel, J., L'Homme, M. C., \& Laneville, M. E. (2012). General and specialized lexical resources: A study on the potential of combining efforts to enrich formal lexicons. International journal of lexicography, 25(2), 152-190. doi: 10.1093/ijl/ecr025

Plant, R., \& Gamble, R. (2003). Methodologies for the development of knowledge-based systems, $1982-2002$. The Knowledge Engineering Review, 18(01), 47-81.

Pojman, L. P. (2001). What can we know. An introduction to the theory of knowledge, 2.

Prado, R., Garc, S., x00Ed, a, G., x00E, Yuste, A., . . Bruque, S. (2010, 17-19 March 2010). Genetic Fuzzy Rule-Based meta-scheduler for Grid computing. Paper presented at the Genetic and Evolutionary Fuzzy Systems (GEFS), 2010 4th International Workshop on.

Prado, R., Garcia-Gala, S., x, Exp, J., x00F, sito, \& Yuste, A. (2010). Knowledge Acquisition in Fuzzy-RuleBased Systems With Particle-Swarm Optimization. Ieee Transactions on Fuzzy Systems, 18(6), 1083 1097. doi: 10.1109/TFUZZ.2010.2062525

Prado, R. P., Garc, S., x00Ed, a, G., x00E, Exp, J. E. M., . . sito. (2011, 11-15 April 2011). KASIA approach vs. Differential Evolution in Fuzzy Rule-Based meta-schedulers for Grid computing. Paper presented at the Genetic and Evolutionary Fuzzy Systems (GEFS), 2011 IEEE 5th International Workshop on.

Prakash, R. S. S., Jurafsky, D., \& Ng, A. Y. (2007). Learning to merge word senses. EMNLP-CoNLL 2007, 1005.

Prud'Hommeaux, E., \& Seaborne, A. (2008). SPARQL query language for RDF. W3C recommendation, 15.

Ramakrishnan, C., Patnia, A., Hovy, E., \& Burns, G. A. P. C. (2012). Layout-aware text extraction from fulltext PDF of scientific articles. Source Code for Biology and Medicine, 7. doi: 10.1186/1751-0473-7-7 
Ramirez, C., \& Valdes, B. (2012). A general knowledge representation model of concepts: INTECH Open Access Publisher.

Ramos, L. (2015). Semantic Web for manufacturing, trends and open issues: Toward a state of the art. Computers and Industrial Engineering, 90, 444-460. doi: 10.1016/j.cie.2015.10.013

Rattanasawad, T., Saikaew, K. R., Buranarach, M., \& Supnithi, T. (2013, 4-6 Sept. 2013). A review and comparison of rule languages and rule-based inference engines for the Semantic Web. Paper presented at the Computer Science and Engineering Conference (ICSEC), 2013 International.

Rehman, Muhammad Habib ur, Chang, V., Batool, A., \& Teh, Y. W. (2016). Big Data Reduction Framework

for Value Creation in Sustainable

Enterprises. International Journal of Information Management.

Robles, K., Fraga, A., Morato, J., \& Llorens, J. (2012). Towards an ontology-based retrieval of UML Class Diagrams. Information and Software Technology, 54(1), 72-86.

Ruppenhofer, J., Ellsworth, M., Petruck, M. R., Johnson, C. R., \& Scheffczyk, J. (2006). FrameNet II: Extended theory and practice.

Ruppenhofer, J., Sporleder, C., Morante, R., Baker, C., \& Palmer, M. (2010). Semeval-2010 task 10: Linking events and their participants in discourse. Paper presented at the Proceedings of the 5th International Workshop on Semantic Evaluation.

Sachdeva, P., Verma, S., \& Singh, S. K. (2014, 15-17 Dec. 2014). An improved approach to word sense disambiguation. Paper presented at the Signal Processing and Information Technology (ISSPIT), 2014 IEEE International Symposium on.

Sahin, S., Tolun, M. R., \& Hassanpour, R. (2012). Hybrid expert systems: A survey of current approaches and applications. Expert Systems with Applications, 39(4), 4609-4617.

Saif, A., Ab Aziz, M. J., \& Omar, N. (2015). Mapping Arabic WordNet synsets to Wikipedia articles using monolingual and bilingual features. Natural Language Engineering. doi: 10.1017/S1351324915000376

Sánchez, D. (2010). A methodology to learn ontological attributes from the Web. Data \& Knowledge Engineering, 69(6), 573-597.

Sánchez, D., \& Moreno, A. (2008). Learning non-taxonomic relationships from web documents for domain ontology construction. Data and Knowledge Engineering, 64(3), 600-623. doi: 10.1016/j.datak.2007.10.001

Santos, L. E., Girardi, R., \& Novais, P. (2013, 15-17 April 2013). A Case Study on the Construction of Application Ontologies. Paper presented at the Information Technology: New Generations (ITNG), 2013 Tenth International Conference on.

Santoso, H. A., Haw, S. C., \& Lee, C. S. (2011) Software reuse: MDA-based ontology development to support data access over legacy applications. Vol. 181 CCIS. Communications in Computer and Information Science (pp. 130-142).

Scaiano, M., \& Inkpen, D. (2009) Automatic frame extraction from sentences. Vol. 5549 LNAI. Lecture Notes in Computer Science (including subseries Lecture Notes in Artificial Intelligence and Lecture Notes in Bioinformatics) (pp. 110-120).

Schuller, B., \& Knaup, T. (2011) Learning and knowledge-based sentiment analysis in movie review key excerpts. Vol. 6456 LNCS. Lecture Notes in Computer Science (including subseries Lecture Notes in Artificial Intelligence and Lecture Notes in Bioinformatics) (pp. 448-472).

Selva, D., Cameron, B., \& Crawley, E. F. (2014). A rule-based method for scalable and traceable evaluation of system architectures. Research in Engineering Design, 25(4), 325-349. doi: 10.1007/s00163-014-0180$\mathrm{X}$

Selva, D., \& Crawley, E. F. (2012, 3-10 March 2012). A rule-based decision support tool for architecting Earth observing missions. Paper presented at the Aerospace Conference, 2012 IEEE.

Semenova, A. V., \& Kureychik, V. M. (2015, 14-16 Oct. 2015). Domain ontology development for linguistic purposes. Paper presented at the Application of Information and Communication Technologies (AICT), 2015.

Sharma S., Chang V., Tim U. S., Wong J., \& Gadia S. (2006) Cloud-based emerging services systems, International Journal of Information Management.

She, L., \& Wang, S. Q. (2009). Geometry knowledge acquisition and representation on ontology. Paper presented at the Proceedings - 2009 International Conference on Computational Intelligence and Software Engineering, CiSE 2009. 
Simperl, E. (2009). Reusing ontologies on the Semantic Web: A feasibility study. Data \& Knowledge Engineering, 68(10), 905-925.

Singh, P., \& Williams, W. (2003). LifeNet: a propositional model of ordinary human activity. Paper presented at the Proceedings of the Workshop on Distributed and Collaborative Knowledge Capture (DC-KCAP) at KCAP.

Sinha, S. K. (2008). Answering Questions about Complex Events: DTIC Document.

Soo-Yeon, L., Mu-Hee, S., Ki-Jun, S., \& Sang-Jo, L. (2004, 2-6 Nov. 2004). Domain ontology construction based on semantic relation information of terminology. Paper presented at the Industrial Electronics Society, 2004. IECON 2004. 30th Annual Conference of IEEE.

Speer, R., \& Havasi, C. (2012). Representing General Relational Knowledge in ConceptNet 5. Paper presented at the LREC.

Studer, R., Benjamins, V. R., \& Fensel, D. (1998). Knowledge engineering: principles and methods. Data \& Knowledge Engineering, 25(1), 161-197.

Su, X., Matskin, M., \& Rao, J. (2003, 13-17 Oct. 2003). Implementing explanation ontology for agent system. Paper presented at the Web Intelligence, 2003. WI 2003. Proceedings. IEEE/WIC International Conference on.

Su, X., Zhu, G., Liu, X., \& Yuan, W. (2005, 27-29 Nov. 2005). Presentation of Programming Domain Knowledge with Ontology. Paper presented at the Semantics, Knowledge and Grid, 2005. SKG '05. First International Conference on.

Temal, L., Dojat, M., Kassel, G., \& Gibaud, B. (2008). Towards an ontology for sharing medical images and regions of interest in neuroimaging. Journal of Biomedical Informatics, 41(5), 766-778.

Tenorth, M., \& Beetz, M. (2013). KnowRob: A knowledge processing infrastructure for cognition-enabled robots. The International Journal of Robotics Research, 32(5), 566-590. doi: $10.1177 / 0278364913481635$

Tian, Y., \& Wang, Y. (2007, 6-8 Aug. 2007). A Knowledge Representation Tool Based on Concept Algebra. Paper presented at the Cognitive Informatics, 6th IEEE International Conference on.

Tian, Y., Wang, Y., Gavrilova, M. L., \& Ruhe, G. (2011, 18-20 Aug. 2011). A formal knowledge representation system for the cognitive learning engine. Paper presented at the Cognitive Informatics \& Cognitive Computing (ICCI*CC ), 2011 10th IEEE International Conference on.

Tsai, A. C. R., Wu, C. E., Tsai, R. T. H., \& Hsu, J. Y. j. (2013). Building a Concept-Level Sentiment Dictionary Based on Commonsense Knowledge. Ieee Intelligent Systems, 28(2), 22-30. doi: 10.1109/MIS.2013.25

Tyar, S. M., \& Win, T. (2015, 29-30 Oct. 2015). Jaccard coefficient-based word sense disambiguation using hybrid knowledge resources. Paper presented at the 20157 th International Conference on Information Technology and Electrical Engineering (ICITEE).

Uddin, M. N., Duong, T. H., Nguyen, N. T., Qi, X. M., \& Jo, G. S. (2013). Semantic similarity similarity measures for enhancing information retrieval in folksonomies. Expert Systems with Applications, 40(5), 1645-1653.

Ustundag, A., Kilinc, M. S., \& Cevikcan, E. (2010). Fuzzy rule-based system for the economic analysis of RFID investments. Expert Systems with Applications, 37(7), 5300-5306.

Valipour, M., \& Yingxu, W. (2015, 6-8 July 2015). Formal properties and rules of concept algebra. Paper presented at the Cognitive Informatics \& Cognitive Computing (ICCI*CC), 2015 IEEE 14th International Conference on.

Van Assem, M., Gangemi, A., \& Schreiber, G. (2006). Conversion of WordNet to a standard RDF/OWL representation. Paper presented at the Proceedings of the Fifth International Conference on Language Resources and Evaluation (LREC'06), Genoa, Italy.

Van Heijst, G., Schreiber, A. T., \& Wielinga, B. J. (1997). Using explicit ontologies in KBS development. International Journal of Human-Computer Studies, 46(2), 183-292.

Vo, D. T., Hai, V. T., \& Ock, C. Y. (2015). Exploiting Language Models to Classify Events from Twitter. Computational Intelligence and Neuroscience, 2015. doi: 10.1155/2015/401024

Vossen, P. (1997). EuroWordNet: a multilingual database for information retrieval. Paper presented at the Proceedings of the DELOS workshop on Cross-language Information Retrieval.

Wandmacher, T., Ovchinnikova, E., Mönnich, U., Michaelis, J., \& Kühnberger, K. U. (2011) Adaptation of ontological knowledge from structured textual data. Vol. 370. Studies in Computational Intelligence (pp. 129-153). 
Wang, Y. (2007). The OAR model of neural informatics for internal knowledge representation in the brain. International Journal of Cognitive Informatics and Natural Intelligence (IJCINI), 1(3), 66-77.

Wang, Y. (2008). On concept algebra: A denotational mathematical structure for knowledge and software modeling. International Journal of Cognitive Informatics and Natural Intelligence (IJCINI), 2(2), 1-19.

Wang, Y. (2014). On a Novel Cognitive Knowledge Base (CKB) for Cognitive Robots and Machine Learning. International Journal of Software Science and Computational Intelligence (IJSSCI), 6(2), 41-62.

Wang, Y. (2015a). Concept Algebra: A Denotational Mathematics Revisited for Formal Knowledge Representation and Cognitive Machine Learning. Cognitive Linguistics, Cognitive Robots, and Computational Intelligence, Journal of Advanced Mathematics and Applications, 4(1).

Wang, Y. (2015). Formal Cognitive Models of Data, Information, Knowledge, and Intelligence. WSEAS Transaction on Computers.

Wang, Y. (2015b). Towards the Abstract System Theory of System Science for Cognitive and Intelligent Systems. Springer Journal of Complex and Intelligent Systems.

Wang, Y., Tian, Y., \& Hu, K. (2011, 18-20 Aug. 2011). The operational semantics of Concept Algebra for cognitive computing and machine learning. Paper presented at the Cognitive Informatics \& Cognitive Computing (ICCI*CC ), 2011 10th IEEE International Conference on.

Wei, L., Zong-Tian, L., \& Kun, S. (2003, 2-5 Nov. 2003). UML-based domain ontology modeling for multiagent system. Paper presented at the Machine Learning and Cybernetics, 2003 International Conference on.

Wei, T. T., Lu, Y. H., Chang, H. Y., Zhou, Q., \& Bao, X. Y. (2015). A semantic approach for text clustering using WordNet and lexical chains. Expert Systems with Applications, 42(4), 2264-2275.

Wielemaker, J., Huang, Z., \& Van Der Meij, L. (2008). SWI-Prolog and the Web. Theory and Practice of Logic Programming, 8(03), 363-392.

Wielinga, B. J., Schreiber, A. T., \& Breuker, J. A. (1992). KADS: A modelling approach to knowledge engineering. Knowledge acquisition, 4(1), 5-53.

Wilson, R. A., \& Keil, F. C. (2001). The MIT encyclopedia of the cognitive sciences: MIT press.

Wu, C. E., \& Tsai, R. T. H. (2014). Using relation selection to improve value propagation in a ConceptNetbased sentiment dictionary. Knowledge-Based Systems, 69(1), 100-107. doi: 10.1016/j.knosys.2014.04.043

Wu, C. G., Xu, X., Zhang, B. K., \& Na, Y. L. (2013). Domain ontology for scenario-based hazard evaluation. Safety Science, 60, 21-34. doi: 10.1016/j.ssci.2013.06.003

Xing, X., Li, R., \& Liu, K. (2009, 17-19 Oct. 2009). Building Ontology Base on Thesaurus. Paper presented at the Biomedical Engineering and Informatics, 2009. BMEI '09.

Yaqoob I., Chang V., Gani A., Mokhtar S., Hashem I.A.T, Ejaz Ahmed, Anuar N.B., Khan S.U. (2016) Information fusion in social big data: Foundations, state-of-the-art, applications, challenges, and future research directions, International Journal of Information Management.

Ye, F., Xiong, J., \& Xu, L. (2013, 20-23 Aug. 2013). A Text Association Rules Mining Method Based on Concept Algebra. Paper presented at the Green Computing and Communications (GreenCom), 2013 IEEE and Internet of Things (iThings/CPSCom), IEEE International Conference on and IEEE Cyber, Physical and Social Computing.

Ye, J., Stevenson, G., \& Dobson, S. (2011). A top-level ontology for smart environments. Pervasive and Mobile Computing, 7(3), 359-378.

Zajaczkowski, J., \& Verma, B. (2012). Selection and impact of different topologies in multi-layered hierarchical fuzzy systems. Applied Intelligence, 36(3), 564-584.

Zhang, C. X., Cao, C. G., Gu, F., \& Si, J. X. (2004). Domain-specific formal ontology. of archaeology and its application in knowledge acquisition and analysis. Journal of Computer Science and Technology, 19(3), 290-301. doi: 10.1007/bf02944899

Zhang, C. X., Cao, C. G., Sui, Y. F., \& Wu, X. D. (2011). A Chinese time ontology for the Semantic Web. Knowledge-Based Systems, 24(7), 1057-1074.

Zhang, F., \& Ma, Z. M. (2014). Representing and Reasoning About XML with Ontologies. Applied Intelligence, 40(1), 74-106.

Zhang, H., \& Zou, Y. (2012, 21-24 May 2012). Integration of dispatch and control based intelligent processing system research for equipment abnormal alarm signals. Paper presented at the Innovative Smart Grid Technologies - Asia (ISGT Asia), 2012 IEEE. 
Zhang, Q. A., \& Mahfouf, M. (2011). A hierarchical Mamdani-type fuzzy modelling approach with new training data selection and multi-objective optimisation mechanisms: A special application for the prediction of mechanical properties of alloy steels. Applied Soft Computing, 11(2), 2419-2443.

Zhang, X., Yang, Y., Zhang, Y., Luan, H., Li, J., Zhang, H., \& Chua, T. S. (2015). Enhancing Video Event Recognition Using Automatically Constructed Semantic-Visual Knowledge Base. Ieee Transactions on Multimedia, 17(9), 1562-1575. doi: 10.1109/TMM.2015.2449660

Zhou, L. (2007). Ontology learning: state of the art and open issues. Information Technology and Management, $8(3), 241-252$.

Zhou, S.-M., Lyons, R. A., Brophy, S., \& Gravenor, M. B. (2012). Constructing compact Takagi-Sugeno rule systems: identification of complex interactions in epidemiological data. Plos One, 7(12), e51468. 